\title{
TU/e EN⿴HONE

\section{Experimental and numerical analyses of liquid and spray penetration under heavy-duty diesel engine conditions}

\section{Citation for published version (APA):}

Maes, N. C. J., Dam, N. J., Somers, L. M. T., Lucchini, T., D'Errico, G., \& Hardy, G. (2016). Experimental and numerical analyses of liquid and spray penetration under heavy-duty diesel engine conditions. SAE International Journal of Fuels and Lubricants, 9(1), 108-124. https://doi.org/10.4271/2016-01-0861

DOI:

10.4271/2016-01-0861

Document status and date:

Published: 01/04/2016

\section{Document Version:}

Accepted manuscript including changes made at the peer-review stage

\section{Please check the document version of this publication:}

- A submitted manuscript is the version of the article upon submission and before peer-review. There can be important differences between the submitted version and the official published version of record. People interested in the research are advised to contact the author for the final version of the publication, or visit the $\mathrm{DOI}$ to the publisher's website.

- The final author version and the galley proof are versions of the publication after peer review.

- The final published version features the final layout of the paper including the volume, issue and page numbers.

Link to publication

\section{General rights}

Copyright and moral rights for the publications made accessible in the public portal are retained by the authors and/or other copyright owners and it is a condition of accessing publications that users recognise and abide by the legal requirements associated with these rights.

- Users may download and print one copy of any publication from the public portal for the purpose of private study or research.

- You may not further distribute the material or use it for any profit-making activity or commercial gain

- You may freely distribute the URL identifying the publication in the public portal.

If the publication is distributed under the terms of Article 25fa of the Dutch Copyright Act, indicated by the "Taverne" license above, please follow below link for the End User Agreement:

www.tue.nl/taverne

Take down policy

If you believe that this document breaches copyright please contact us at:

openaccess@tue.nl

providing details and we will investigate your claim. 


\title{
Experimental and Numerical Analyses of Liquid and Spray Penetration under Heavy-Duty Diesel Engine Conditions
}

\author{
Author, co-author (Do NOT enter this information. It will be pulled from participant tab in \\ MyTechZone) \\ Affiliation (Do NOT enter this information. It will be pulled from participant tab in MyTechZone)
}

\begin{abstract}
The modeling of fuel sprays under well-characterized conditions relevant for heavy-duty Diesel engine applications, allows for detailed analyses of individual phenomena aimed at improving emission formation and fuel consumption. However, the complexity of a reacting fuel spray under heavy-duty conditions currently prohibits direct simulation. Using a systematic approach, we extrapolate available spray models to the desired conditions without inclusion of chemical reactions. For validation, experimental techniques are utilized to characterize inert sprays of n-dodecane in a high-pressure, high-temperature $(900 \mathrm{~K})$ constant volume vessel with full optical access. The liquid fuel spray is studied using high-speed diffused back-illumination for conditions with different densities (22.8 and $40 \mathrm{~kg} / \mathrm{m}^{3}$ ) and injection pressures (150, 80 and $160 \mathrm{MPa}$ ), using a $0.205-\mathrm{mm}$ orifice diameter nozzle. High-speed Schlieren imaging is used to analyze the influence of these boundary conditions on the spray penetration. Simulations of the fuel spray are performed using a dedicated computational mesh with refinements at the known location of the jet to capture the smallest scales of interest. Using a blob injection model refined with a primary atomization and secondary breakup model, correct trends and good agreement are achieved for both liquid and spray penetration. The capability of capturing the trends at largely varying boundary conditions with a single computational approach provides a solid base for future work.
\end{abstract}

\section{Introduction}

Over the past decades, heavy-duty Diesel engines have proven to be the primary choice of both manufacturers and customers in the most common applications in the transport and agriculture sectors. This preference is among others due to the large operating range with high power and load capability, while maintaining high efficiency. Nevertheless, the flexibility and fuel efficiency of these engines come at the cost of $\mathrm{NO}_{\mathrm{x}}$ and/or soot, which has been the focus of many studies in the past [1-4]. The trade-off between soot and $\mathrm{NO}_{\mathrm{x}}$ emissions in Diesel engines is quite well understood and has therefore been the primary subject of modeling efforts as well $[5,6]$. Most studies identify fuel-injection parameters as instruments in reducing emissions to acceptable levels, often involving empirical parameter studies. Yet, ever more stringent emission legislations and a desired improvement of fuel efficiency necessitate detailed understanding of the fundamental processes encountered in modern direct-injected Diesel engines. True understanding of these fundamental processes holds the potential of breaching currently accepted trade-offs by avoiding or restricting emission sources and heat losses.

The increasing capability of numerically describing fluid dynamics and turbulent combustion under high-temperature and high-pressure circumstances in a detailed manner, creates possibilities to design future engines based on a high-fidelity computational optimization of relevant parameters. To develop such numerical tools, there is a demand for detailed experiments with well-characterized boundary conditions, which allow direct comparison to assess the model performance. Such detailed experimental results are often obtained using dedicated combustion vessels [7-9]. Combustion vessels are capable of generating relevant, yet simpler boundary conditions while allowing full optical access to investigate a spray with multiple diagnostic techniques in great detail over a long period in time.

In an attempt to combine the strength of experimental and numerical efforts, the Engine Combustion Network (ECN) established a link between different research groups with specific defined test conditions [10]. Using different experimental setups with nominally identical injection equipment, similar results are achieved after due validation of the boundary conditions of the involved combustion vessels within the network $[8,9,11,12]$. On the numerical side, different spray and mixing approaches have been considered and used in combination with different combustion chemistry mechanisms, computational grids and turbulent-chemistry interaction models $[13,14]$.

In this work, a similar close coupling between experimental and numerical efforts is used to investigate and characterize inert fuel sprays under heavy-duty Diesel engine conditions. Heavy-duty conditions with densities in excess of $30 \mathrm{~kg} / \mathrm{m}^{3}$ at temperatures relevant for internal combustion engines have only been sparsely investigated in the past. Significant contributions date back to a period between 1996 and 2001, when scaling laws for liquid length, spray penetration and flame lift-off length were determined [15-18], and more recently in a study to characterize the fluctuations in the liquid penetration of evaporating sprays [19]. The highest densities in the investigated test matrix mostly exceeded actual applications at that time. Nowadays engines start to operate in such range. Achieving relevant conditions for modern heavy-duty Diesel engines in an optically accessible setup requires a robust design [7]. In addition to this, the quality of results obtained by optical diagnostic techniques generally decreases with increased density due to severe beam steering and quenching.

Page 1 of 18 
We first consider the well-known ECN Spray A boundary conditions to investigate the influence of the difference in orifice size by increasing the diameter to a value which is more typical for heavyduty injectors. Like advocated in recent studies [20-26], Diffused Back-Illumination (DBI) is applied in this study to determine the liquid penetration. High-speed Schlieren imaging, which effectively records changes in refractive index is used to determine the spray penetration.

The influence of variation in ambient density and injection pressure on the liquid and jet penetration, obtained by both experimental and numerical work are shown in this paper. Boundary conditions with increased density were implemented and validated using a fast pressure transducer and fine-wire thermocouples as proposed in previous work $[8,9,15-18,27]$. Subsequently, we present and compare the results obtained at the new boundary conditions, establishing a solid base for future work where reacting fuel sprays will be investigated.

\section{Research Approach and Boundary Conditions}

Both experimental and numerical approaches are used in this work to characterize inert, evaporating fuel sprays under heavy-duty Diesel engine conditions. The following sections provide detailed information about the experimental equipment, optical diagnostic techniques, numerical setup, and boundary conditions which have been investigated within the scope of this study.

\section{Experimental Setup}

\section{Combustion Vessel and Injection Equipment}

Experiments were conducted in a high-pressure and high-temperature constant-volume vessel with optical access. The experimental setup is based on a pre-burn type of combustion vessel which achieves precomputed target conditions after the combustion of a reacting gas mixture $[7,28]$. Using this approach, a wide range in operating conditions covering typical Diesel combustion can be achieved and studied. The vessel has a cubical geometry with a volume of nearly 1300 cc where a single orifice common-rail injector is mounted in the center of a metal side port. Full optical access can be provided on all other faces of the cubical volume. The vessel can be equipped with either quartz or sapphire windows, but only the latter were used throughout the entire campaign. When optical access is not required, metal blanks are generally used to reduce reflections. Diagonal ports of the vessel are equipped with two spark-plugs, an rpm-controlled mixing fan (2000 rpm) which is in operation during the entire experiment, a pressure transducer, and intake and exhaust ports.

\section{Optical Diagnostic Techniques}

\section{High-Speed Diffused Back-Illumination imaging}

The liquid penetration was imaged using DBI, which has been proposed as a standard technique for vaporizing diesel sprays by Manin and co-workers [20]. In their investigation, they advocate the technique as a superior method for determining the liquid length (fuel penetration) over the traditional Mie-scattering method. DBI utilizes the extinction of light by the liquid fuel and gives more consistent results between institutes since the images are normalized using a reference image. In this work, the broadband light from a 100-W LED illuminated an engineered diffuser with a $50^{\circ}$ square pattern. The light was subsequently directed towards the spray vessel using a Page 2 of 18
Fresnel lens with a focal length of $152 \mathrm{~mm}$ as illustrated in the upper panel of Figure 1. A high-speed CMOS camera (Photron SA-Z) with a Sigma 105-mm f/2.8 EX lens was used to collect the transmitted light with a frame rate of $160 \mathrm{kHz}$ and a projected pixel size of 77.5 $\mu \mathrm{m} /$ pixel. The LED was not pulsed, since the exposure time of the camera was sufficiently short $(2.5 \mu \mathrm{s})$ to prevent motion blur of the liquid fuel.

\section{High-Speed Schlieren imaging}

The jet penetration of inert fuel sprays was imaged using a brightfield Schlieren imaging setup with two bi-convex lenses of 1000-mm focal length. The setup, illustrated in the bottom panel of Figure 1, uses the same camera, lens and light source as the DBI setup. However, the projected pixel size in this case was increased to 0.22 $\mathrm{mm} /$ pixel due to the optical arrangement. Previous spray related studies show largely different arrangements to capture the Schlieren effects, mostly based on experience, desired sensitivity and experimental conditions [22,23,29,30]. In this work, a 3-mm circular aperture was placed close to the LED to limit the size of the light source. At the detection side, a 4-mm circular aperture with a sharp edge was placed after the focal point to block the refracted light rays. The sizes and exact locations of the apertures were empirically adjusted to optimize the visual quality of the detected images.
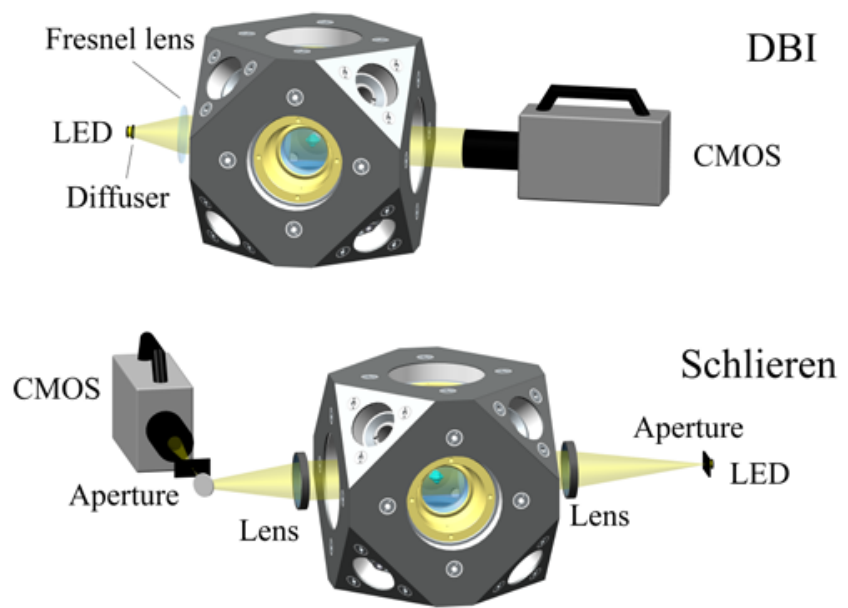

Figure 1. Schematic diagrams of the combustion vessel and the two optical diagnostic techniques used in this work.

\section{Numerical setup}

The Eulerian-Lagrangian approach was employed to model the fuel spray, which is composed of a discrete number of computational parcels, each one formed by an arbitrary number of droplets with the same properties. Each parcel evolves in the computational mesh according to the mass, momentum and energy exchange with the continuous gas phase which is treated in an Eulerian way. Additional phenomenological sub-models are then required to describe the various physical processes taking place on the sub-grid length scales: atomization, secondary breakup, drag, evaporation, heat transfer, collision and turbulent dispersion. Fuel-air mixing simulations were carried out by using the Lib-ICE code, which is a set of libraries and solvers for IC engine modeling based on the OpenFOAM ${ }^{\circledR}$ technology. Over the years it was successfully applied to simulation of spray and combustion in direct-injection engines [31-33]. To describe atomization and secondary breakup, different combinations of sub-models were proposed over the years [34,35], all of them providing reasonably good results both at evaporating and non- 
evaporating conditions when applied to nozzles with diameters typical of passenger car engines. In Heavy Duty engines, nozzle sizes are much larger and expected liquid penetration lengths are larger. Within this context, a proper choice of sub-models, mesh size and turbulence model is of great importance for a proper prediction of the spray evolution, in particular:

- $\quad$ Spray sub-models (atomization and breakup): they regulate the size of the parcels once they leave the nozzle, depending on aerodynamic and turbulent instabilities. Droplet size and velocity then affect the transfer of mass and momentum from the liquid to the gas phase.

- $\quad$ Mesh size: due to larger spray penetration, Lagrangian and Eulerian phases will interact over a larger portion of the computational mesh. This aspect can affect the so-called griddependency phenomenon.

- $\quad$ Turbulence model: when the standard $k-\varepsilon$ model is employed, vapor penetration is generally underestimated. The proposed corrections to model constants generally work well for gas jets or when spray penetration is small. However, the resulting increase of axial turbulent viscosity can negatively affect the predicted relative velocity when large nozzle configurations are simulated.

Following our previous work [32,34,35], separate models were applied to predict atomization and secondary breakup processes. This is expected to better reproduce the morphology and the evolution of sprays emerging from large nozzles.

Concerning atomization, the Huh-Gosman model was used [36,37]. The liquid jet is represented by primary parcels, which are introduced within the computational mesh with a diameter equal to that of the nozzle. Their velocity is a function of the injected mass flow rate profile. Both Kelvin-Helmholtz and turbulence induced breakup on the jet surface are taken into account by the model, describing the diameter reduction of the injected parcels as follows:

$$
\frac{d D_{p}}{d t}=-C_{\varepsilon 5} \frac{L_{a}}{\tau_{a}}
$$

where $C_{\varepsilon 5}$ is the main model constant, $L_{a}$ and $\tau_{a}$ are the characteristic atomization length and time scales. $L_{a}$ is proportional to the turbulent length scale of the liquid jet $L_{t}$ :

$$
L_{a}=C_{\varepsilon 1} L_{t}
$$

while the atomization time-scale is a function of both turbulent and aerodynamic time scales, $\tau_{t}$ and $\tau_{w}$ as follows:

$$
\tau_{a}=C_{\varepsilon 3} \tau_{t}+C_{\varepsilon 4} \tau_{w}
$$

$\tau_{w}$ is expressed according to the Kelvin-Helmholtz instability theory for an inviscid liquid on an infinite plane:

$$
\tau_{w}=\left[\frac{\rho_{l} \rho_{g}}{\left(\rho_{l}+\rho_{g}\right)^{2}}\left(\frac{u_{r e l}}{L_{w}}\right)^{2}-\frac{\sigma_{l}}{\left(\rho_{l}+\rho_{g}\right) L_{w}^{3}}\right]^{-0.5}
$$

where $\rho_{\mathrm{l}}$ and $\rho_{\mathrm{g}}$ are respectively the liquid and gas densities, $\sigma_{\mathrm{l}}$ is the surface tension, and $\mathrm{u}_{\text {rel }}$ the liquid-gas relative velocity. $L_{w}$ is the wavelength of the perturbations on the jet surface, which is assumed to be related to $L_{a}$ according to:

$$
L_{a}=C_{\varepsilon 2} L_{w}
$$

The spray cone angle is computed assuming that the spray diverges with a radial velocity $L_{a} / \tau_{a}$. Hence the cone angle is computed as:

$$
\tan \left(\frac{\alpha}{2}\right)=\frac{L_{a} / \tau_{a}}{\mathrm{U}_{i n j}}
$$

Where $\mathrm{U}_{i n j}$ is the instantaneous jet velocity computed from the injected mass flow rate profile. Once the liquid jet leaves the nozzle, its internal turbulence decays with time, due to the absence of shear stresses. Assuming a homogeneous isotropic turbulence inside the nozzle and applying a zero-dimensional version of the $k-\varepsilon$ model, the turbulence length and time scales evolve in time according to:

$$
\begin{gathered}
L_{t}(t)=L_{t}^{0}\left(1+C_{a 1} \frac{t}{\tau_{t 0}}\right)^{C_{a 2}} \\
\tau_{t}(t)=\tau_{t}^{0}\left(1+C_{a 1} \frac{t}{\tau_{t 0}}\right)
\end{gathered}
$$

where $L_{t}^{0}$ and $\tau_{t}^{0}$ are turbulent length and time-scales at the nozzle exit which are estimated in this work from a simplified nozzle flow model [36,37].

$$
\begin{aligned}
& L_{t}^{0}=C_{\mu} \frac{k_{0}^{1.5}}{\varepsilon_{0}} \\
& \tau_{t}^{0}=C_{\mu} \frac{k_{0}}{\varepsilon_{0}}
\end{aligned}
$$

Where $C_{\mu}=0.09$ is a constant given in the k- $\varepsilon$ model. In the above equations, $\mathrm{k}_{0}$ and $\varepsilon_{0}$ are estimated as follows:

$$
\begin{aligned}
& k_{0}=\frac{U_{i n j}^{2}}{8 L / D}\left[\frac{1}{C_{d}^{2}}-K_{c}-\left(1-s^{2}\right)\right] \\
& \varepsilon_{0}=K_{\varepsilon} \frac{U_{i n j}^{3}}{2 L}\left[\frac{1}{C_{d}^{2}}-K_{c}-\left(1-s^{2}\right)\right]
\end{aligned}
$$

Where $C_{d}$ is the discharge coefficient, $K_{\varepsilon}$ is a model constant, $K_{c}$ and $s$ are the form loss coefficient and the area ratio at the contraction corner, which depends on the nozzle design. $L$ and $D$ are the nozzle hole length and diameter, respecitvely. $C_{a 1}$ and $C_{a 2}$ are additional model constants describing the turbulence evolution on the liquid jet once it leaves the nozzle. As a consequence of the parent droplet diameter reduction, new droplets are created. The total amount of mass stripped from each parent droplet is computed as:

$$
m_{s}=\rho_{l} n_{p} \frac{\pi}{6}\left(D_{\text {old }}^{3}-D_{\text {new }}^{3}\right)
$$

where $n_{p}$ is the total number of parent droplets constituting the liquid core. New parcels representing these stripped droplets are created when the total stripped mass is higher than a specific threshold, set to be equal to 0.1 times the original parent parcel mass, following [36]. Secondary droplet diameter is computed from a PDF distribution which was created with the following assumptions: 
- $\quad$ The number of droplets of size $x$ is inversely proportional to the atomization time-scale $\tau_{a}$;

- $\quad$ The number of droplets of size $x$ is proportional to the jet-todroplet surface area-ratio $D_{d}^{2} / x$;

- The number of droplets of size $x$ is proportional to the dimensionless turbulent energy spectrum [38];

- $\quad$ The number of size in the range $(x, x+d x)$ is proportional to the unit size interval, $d x / x$.

The maximum diameter of the droplet size distribution is assumed to be the parent parcel one while the minimum diameter is computed as:

$$
d_{\text {min }}=2 \pi \frac{\left(\rho_{l}+\rho_{g}\right) \sigma_{L}}{\rho_{l} \rho_{g} u^{2}}
$$

Secondary droplets inherit velocity from their parents, and the atomization process is supposed to cease as soon as one of the following conditions is satisfied: parent droplet diameter lower than the atomization length scale, Weber number $(W e)$ lower than 40 or Ohnesorge number $(\mathrm{Oh})$ greater than 2 [39]. Parent droplets are not subject to drag, evaporation and heat transfer.

To better understand the effects of the atomization process on the spray evolution, two different approaches were used to initialize the velocity direction of the parent and secondary droplets. In the first one, the direction of the primary parcels is randomly chosen between 0 and initial spray angle $\alpha$, computed at the nozzle exit; secondary droplets then inherit velocity from their parents when they are stripped. In the second approach, primary parcels only have the axial component. At the time the stripping process takes place, secondary droplets are deflected with a radial velocity $v_{r}=L_{a} / \tau_{a}$, which takes into account both turbulence at the nozzle exit and its progressive decay when traveling downstream. This is expected to better predict the spray morphology resulting from atomization.

The PDF distribution resulting from the previous assumptions mainly relates the size of the secondary droplets to the size of the eddies generated by the turbulence on the jet surface, with computed diameters ranging between 0.01 to 0.2 times the original jet diameter. The Huh-Gosman model capability to account for liquid jet turbulence on the atomization process makes it very suitable for coupled Lagrangian/nozzle-flow simulations whose predictive capabilities for spray modeling are expected to be very high [40-42].

The model originally proposed by Pilch and Erdman was applied in this work to predict the secondary breakup process [43]. According to their approach, there is a maximum stable diameter $D_{s}$ below which breakup does not take place. The value of $D_{s}$ is affected in two ways: (i) the decrease of droplet Weber number because of the new smaller droplet diameter and (ii) the decrease in relative velocity between the droplets and the flow-field, due to the changes in droplet acceleration (as a results of the decreased droplet diameter). The droplet breakup occurs if the decrease in Weber number is greater than a critical value $W e_{c}$, accounting for the viscous effects parameterized by the Ohnesorge number as follows:

$$
W e_{c}=6\left(1+1.0770 h^{1.6}\right)
$$

The Pilch-Erdman model distinguishes between five breakup regimes: each one of them is characterized by dimensionless total breakup time $\bar{\tau}_{b}$ as follows as illustrated in Table 1 .
Table 1. Dimensionless breakup time values for different Weber number ranges as suggested by the Pilch-Erdman breakup model.

\begin{tabular}{|l|c|c|}
\hline \multicolumn{1}{|c|}{ Type } & Breakup time $\overline{\boldsymbol{\tau}}_{\boldsymbol{b}}$ & Weber number range \\
\hline Vibrational breakup & $6(2 W e-12)^{-0.25}$ & $6<W e \leq 9$ \\
\hline Bag breakup & $2.45(2 W e-12)^{0.25}$ & $9<W e \leq 22$ \\
\hline Bag-and-stamen breakup & $14.1(2 W e-12)^{-0.25}$ & $22<W e \leq 75$ \\
\hline Sheet stripping & $0.766(2 W e-12)^{0.25}$ & $175<W e \leq 1335$ \\
\hline Wave crest stripping & 5.5 & $1335<W e$ \\
\hline
\end{tabular}

The dimensionless breakup time $\bar{\tau}_{b}$ depends on several parameters: liquid and gas densities $\left(\rho_{l}\right.$ and $\left.\rho_{g}\right)$, droplet diameter $D_{d}$ and the magnitude of the liquid-gas relative velocity $u_{r e l}$ :

$$
\bar{\tau}_{b}=\tau_{b} \frac{u_{r e l}}{D_{d}}\left(\frac{\rho_{g}}{\rho_{l}}\right)^{1 / 2}
$$

The stable diameter is evaluated from:

$$
D_{s}=2 W e_{c} \frac{\sigma_{l}}{\rho_{g} u_{r e l}^{2}\left(1-\frac{V_{d}}{u_{r e l}}\right)^{-2}}
$$

where the droplet volume $V_{d}$ is given by:

$$
V_{d}=u_{r e l}\left(\frac{\rho_{g}}{\rho_{l}}\right)^{1 / 2}\left(B_{1} \bar{\tau}_{b}+B_{2} \bar{\tau}_{b}^{2}\right)
$$

Coefficients $B_{1}$ and $B_{2}$ have to be tuned to fit experimental data. The change in the diameter of the secondary diameter droplets becomes:

$$
\frac{d D_{d}}{d t}=\frac{D_{d}-D_{s}}{\tau_{b}}
$$

For what concerns the other sub-models employed, heat transfer was predicted using the Ranz-Marshall correlation, evaporation rate is computed from Spalding number. Collision is neglected since it does not significantly affect the spray behavior in evaporating sprays.

\section{Boundary conditions}

The boundary conditions in this work were carefully selected such that both a connection to the existing ECN database and expansion to heavy-duty applications are possible. Furthermore, the effect of single parameters can be studied and compared to literature using the proposed approach. As a single component reference fuel, ndodecane $(\mathrm{C} 12 \mathrm{H} 26)$ is used, because of its physical properties and availability of detailed reaction mechanisms. Furthermore, ndodecane is fluorescence-free and compatible with high-pressure fuel pumping systems. Similar to previous work, ECN Spray A conditions are applied with an ambient temperature of $900 \mathrm{~K}$, an ambient density of $22.8 \mathrm{~kg} / \mathrm{m}^{3}$ and a fuel injection pressure of $150 \mathrm{MPa}[9,22]$. In the present work, however, the injector has an orifice diameter size of $0.205 \mathrm{~mm}$, compared to the 0.09 -mm ECN standard. The used singlehole injector has an orifice which is nominally identical to those in heavy-duty nozzles with multiple holes which are currently in 
production. The injector has a converging hole (k-factor 1.5) and was subjected to hydro-erosive grinding to suppress cavitation as well as possible [44]. Preliminary simulations with a multiphase flow solver including cavitation modeling were performed to investigate the flow in nozzles which are similar to the ones used in this work. Using the approach suggested in [45] and considering operating conditions close to the studied cases, no cavitation was found. Furthermore, in this work, emphasis is laid upon numerically reproducing the liquid and vapor distribution obtained from experiments. Cavitation effects, if any, are obviated by tuning the models to fit experiments, which warrants realistic mixture fracture distributions for combustion studies. The abbreviation ANR refers to the non-reacting injections at ECN Spray A conditions with the large orifice injector. The heavyduty cases feature similar boundary conditions but with a density of $40 \mathrm{~kg} / \mathrm{m}^{3}$ and using two different injection pressures (C1 and C2). Variations in injected fuel mass were matched with realistic operating points for heavy-duty applications. Due to a mechanical failure of the fuel injector, it had to be replaced during the experimental campaign with a nominally identical piece. Because of this replacement, the ndodecane in the fuel system was also refreshed, which revealed that the old fuel had changed color over time. Liquid and spray penetration measurements were compared to the old injector for one of the boundary conditions, in order to check consistency with the preceding experiments. To distinguish this validation condition from the results with the original injector, it will be referred to as C1v. A summary of the conditions applied in this study are listed in Table 2, where injector number 2 refers to the replacement piece.

Table 2. Details of the inert boundary conditions which have been investigated using an injector with an orifice diameter of $0.205 \mathrm{~mm}$. Experiments with the second injector at the condition called "FPT C1" are referred to as C1v throughout the paper, which indicates the validation of the C1 case. The Spray A condition is often indicated with ANR, to indicate the non-reacting environment.

\begin{tabular}{|l|c|c|c|}
\cline { 2 - 4 } \multicolumn{1}{c|}{} & Spray A (ANR) & FPT C1 & FPT C2 \\
\hline Injector numbers & 1 & $1,2(\mathrm{C} 1 \mathrm{v})$ & 2 \\
\hline Ambient temperature [K] & 900 & 900 & 900 \\
\hline Ambient density [kg/m $\left.{ }^{3}\right]$ & 22.8 & 40 & 40 \\
\hline Approximate pressure [MPa] & 6 & 10.5 & 10.5 \\
\hline Fuel injection pressure [MPa] & 150 & 80 & 160 \\
\hline Injection duration [ms] & 4.8 & 5.2 & 4.9 \\
\hline Injected fuel mass [mg] & 60.8 & 46.8 & 64.8 \\
\hline
\end{tabular}

\section{Results and Discussion}

First, the methods for image processing and evaluating experimental parameters is discussed. Characteristic parameters are compared with available literature and influences on the results are evaluated. Then the numerical models are assessed and the determination of parameters which can be related to experiments are defined and explained. Finally, penetration and morphology of liquid- and evaporated fuel sprays obtained from experiments and calculations are compared against each other, and improvements and interests for future studies are identified.

\section{Experimental Liquid Penetration}

Following the work of Manin, we will interpret the DBI images in terms of extinction, noting that both absorption and (large-angle) scattering with contribute to this. To obtain a quantitative value of the optical thickness $\tau^{*}$, the images $I_{i}$ acquired using the high-speed DBI setup (index $i$ labels the frames) are processed using the background image $I_{b g}$ before the start of injection according to

$$
\tau^{*}=-\ln \left(\frac{I_{i}}{I_{b g}}\right) .
$$

A time sequence shortly after the Start Of Injection (SOI) is presented in the left panel of Figure 2. This figure illustrates how the penetration of liquid fuel can be identified by a sharp gradient in the detected extinction. This is the case until the liquid jet approaches its maximum length at around $0.15 \mathrm{~ms}$ after SOI for this condition (C1). As soon as this happens, large fluctuations in liquid penetration are observed due to the detachment of ligaments, as shown in the right panel of this figure. Research dedicated to these fluctuations at similar boundary conditions, but with slightly lower ambient density $\left(34.8 \mathrm{~kg} / \mathrm{m}^{3}\right)$ and injector orifice diameter $(0.145 \mathrm{~mm})$, reported fluctuations on the order of $10 \%$ with respect to the mean liquid length, using the Mie-scattering technique [19]. The main reason for these fluctuations was identified as the spray-induced turbulent eddies at the periphery of the sprays, which was substantiated using large-eddy simulations. Fluctuations in the order of $10 \%$ can easily be distinguished in the image sequence of Figure 2. Also, this sequence shows that the detaching ligaments indeed seem to have a size in the same order of magnitude as the large scale eddies observed at the periphery of the main liquid core. Two of such detaching ligaments are indicated with brackets in Figure 2.
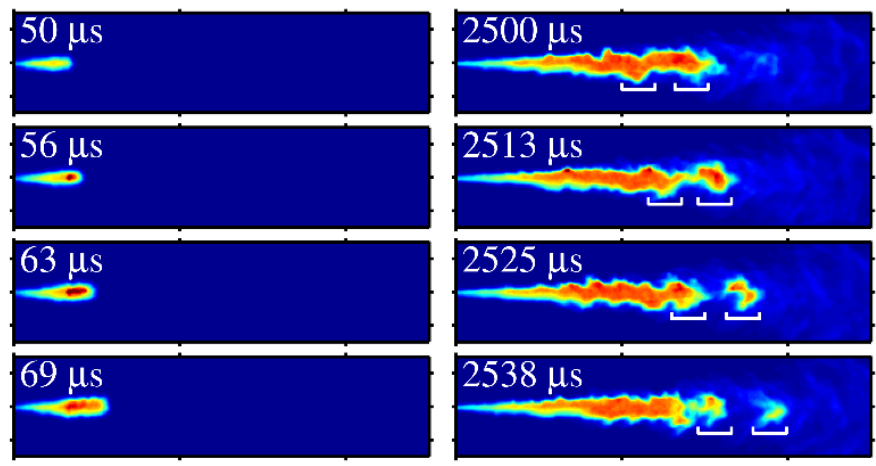

0

10

20

0

10

20

Figure 2. Two time sequences in a false color-scale from a single FPT C1 experiment: $\rho=40 \mathrm{~kg} / \mathrm{m}^{3}, \mathrm{~T}=900 \mathrm{~K}$, injection pressure $=80 \mathrm{MPa}$. The right sequence shows an example of the fluctuations encountered during the quasisteady period of the injection. The white brackets indicate two large eddies which eventually detach.

Despite large fluctuations at the end of a non-interrupted liquid core, the spray is often referred to as quasi-steady, due to a relatively constant mean length, traditionally called the Liquid Length (LL). To quantify this LL, results are generally time-averaged during the quasi-steady phase. The resulting average optical thickness along the spray axis is seen to decline steeply at the end of the liquid jet, as illustrated in Figure 3. As proposed by Manin and co-workers, the interception of a linear fit through this steep decline with the abscissa (where the optical thickness is zero), is defined as the quasi-steady LL. Using such an approach results in a robust parameter which can be used to validate models. For the determination of the transient liquid penetration a fixed optical thickness threshold is generally used, since the fluctuations in instantaneous images prevent the use of a fitting procedure. However, the derived length is then depending

Page 5 of 18 
on the optical depth of the liquid fuel spray and sensitive to the errors induced by optical setup and technique, as discussed in previous studies $[20,25,26,46]$.

Qualitatively, all different optical thickness profiles in Figure 3 show a similar behavior. However, this figure reveals how the results obtained with fresh fuel and a new injector result in a reduction of the detected optical thickness value by nearly $50 \%$. Maximum values in literature, obtained at Spray A boundary conditions with an injector having an orifice diameter of $0.09 \mathrm{~mm}$, range between 2.5 and 3.0 [20-22]. With more than twice the injector orifice diameter in the current work, and therefore more than twice the path length through the liquid volume, one should expect higher values for the optical thickness. This is not the case for the new injector and fuel supply. This decrease is most probably due to the increased transparency of the new fuel. Note that the fitting procedure used to determine the LL is relatively insensitive to small variations in the absolute optical thickness.

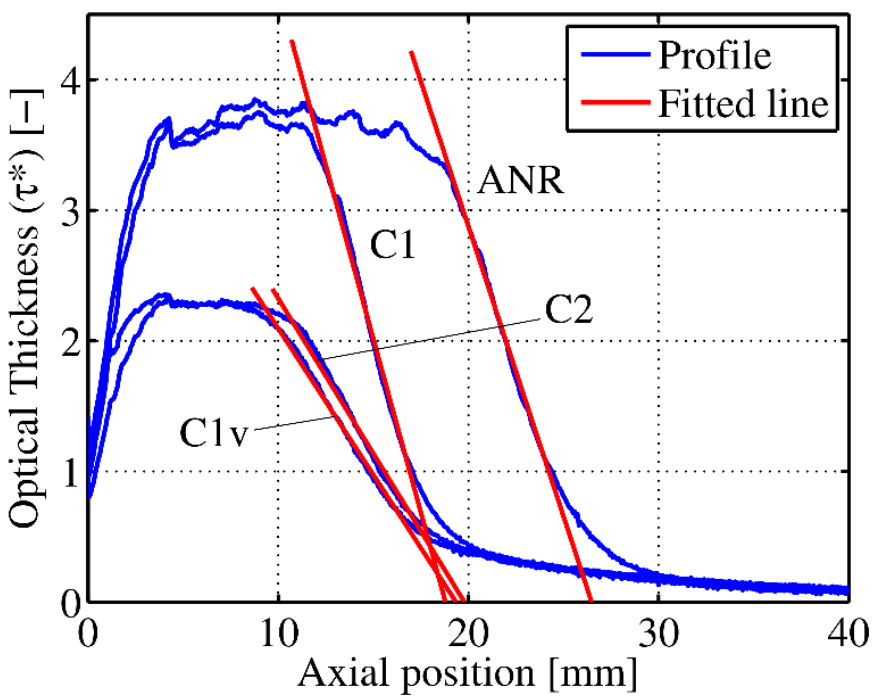

Figure 3. Average profiles of the optical thickness along the injector spray axis for the conditions listed in Table 2. The fitted lines indicate the procedure to determine the quasi-steady liquid length.

Table 3. Liquid length values determined using the fitted line in Figure 3. The lower row indicates 95\% confidence values calculated using a t-distribution. The liquid length value and confidence interval for ECN ANR can be found in the online ECN data library [10].

\begin{tabular}{|l|c|c|c|c|c|}
\cline { 2 - 6 } \multicolumn{1}{c|}{} & ANR & C1 & C1v & C2 & ECN ANR \\
\hline LL [mm] & 26.42 & 18.77 & 19.26 & 19.74 & 10.53 \\
\hline 95\% CI [mm] & 0.36 & 0.27 & 0.55 & 0.21 & 0.39 \\
\hline
\end{tabular}

The resulting liquid length values are listed in Table 3. Averages and confidence intervals are based on 10 individual experiments, with exception of the $\mathrm{C} 1 \mathrm{v}$ case where 5 realizations were taken. As a reference, the value obtained with the ECN nozzle is reported as well to illustrate the influence of the nozzle orifice size $(0.205 \mathrm{~mm}$ compared to the ECN $0.09 \mathrm{~mm}$ ). Previous studies have indicated that there is a near linear relation between injector orifice diameter and the liquid length at a given boundary condition in the mixing limited regime [16,17], which is borne out by these results as well. Furthermore, these previous investigations reported negligible differences due to changes in injection pressure. This is due to the enhanced mixing when the injection rate increases which counterbalances the effect of the higher momentum itself. This, too, is borne out by the results in Table 3, with essentially equal liquid length values obtained for the $\mathrm{C} 1$ and $\mathrm{C} 2$ cases, while the injection pressure differs by $80 \mathrm{MPa}$.

\section{Experimental Vapor Penetration}

Despite the capability of imaging the transparent fuel after evaporation, images detected by a Schlieren setup in a constant volume vessel suffer from an undesired background. The typically observed disturbances result from temperature gradients in the boundary layer at the windows [47]. This becomes more severe in experiments at higher density and ambient temperature, as reported in other studies [15,29,46]. The background disturbances at a given temperature increase with density for mainly two reasons: 1) the differences in density between the fuel and the ambient are reduced and 2) the background structures themselves appear confined to smaller scales. However, due to the relatively low gas velocities inside the vessel (below $1 \mathrm{~m} / \mathrm{s}$ ), the disturbances move slow in comparison with the injected fuel jet.

The jet penetration is retrieved by subtracting the previous image $I_{i-1}$ from the current image $I_{i}$. The result of this subtraction will show the effective progress of the spray, where the quasi-stationary background has largely been cancelled out, illustrated in the upper images of Figure 4. Subsequently, a profile is generated by summing the intensity of the resulting image along the vertical direction (perpendicular to the spray), which is shown in the bottom display of the figure. Similar to the determination of the quasi-steady LL, the spray penetration is defined as the interception of a curve fitted through the decreasing flank of the gradient with the horizontal axis.
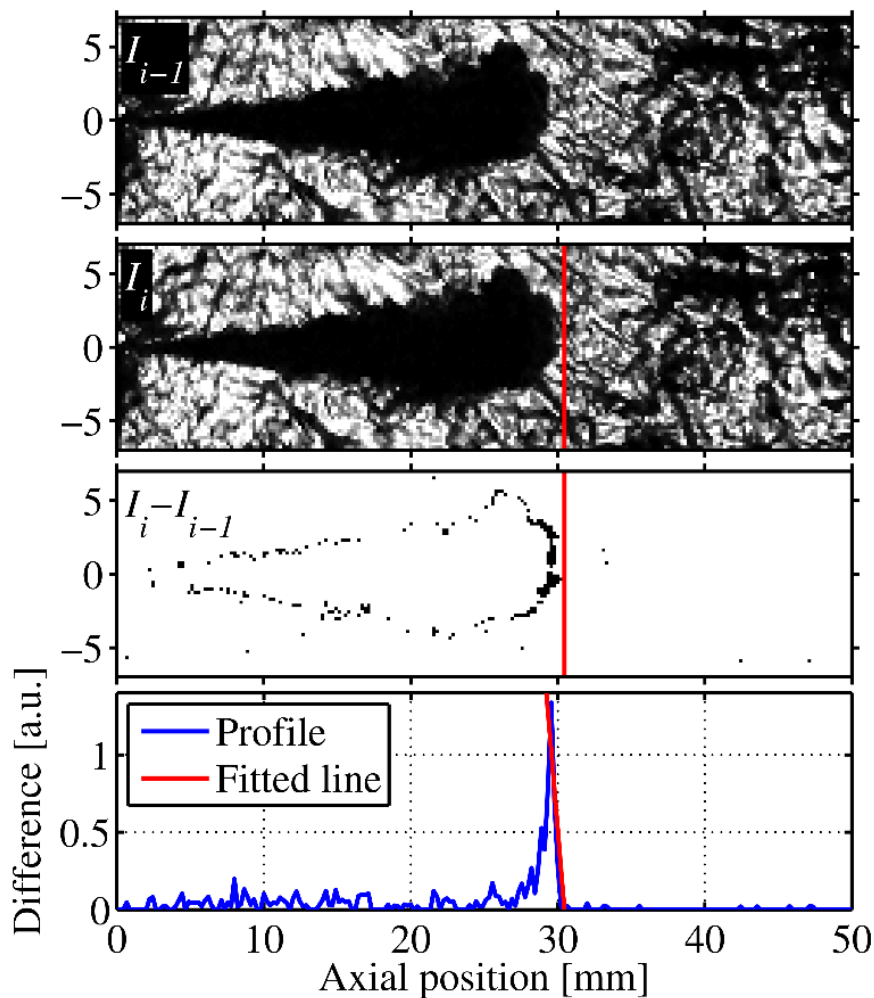

Figure 4. Procedure to determine the spray penetration. From top to bottom: previous image $\left(I_{i-1}\right)$, current image $\left(I_{i}\right)$, resulting contour using a timedifferencing approach $\left(I_{i}-I_{i-1}\right)$, the difference profile obtained by summing

Page 6 of 18 
the columns in the contour image. The red line in the bottom image illustrates the fitting procedure to obtain the spray penetration, the other red lines indicate this value. Experimental conditions: ANR case, 250 us after SOI.

The detected spray penetration, using the method illustrated in Figure 4, is reported in Figure 5. Light-colored regions around the averages indicate $95 \%$ confidence intervals, based on 7 to 11 experiments. The $\mathrm{C} 1 \mathrm{v}$ case is based on the average of 2 experiments, and therefore, no confidence intervals are shown. However, the average of C1v falls within the confidence interval of the $\mathrm{C} 1$ results sufficiently to warrant comparability between the two different injectors.

To compare the morphology of the spray, a different approach is used. Ensemble averaged images enhance the discernibility of the jet by utilizing the nominally identical fuel spray and the apparently random background Schlieren effects. This procedure comes at the cost of the capability to study turbulent structures and fluctuations. However, for the sake of a comparative examination with the RANS models, this method provides a better basis.

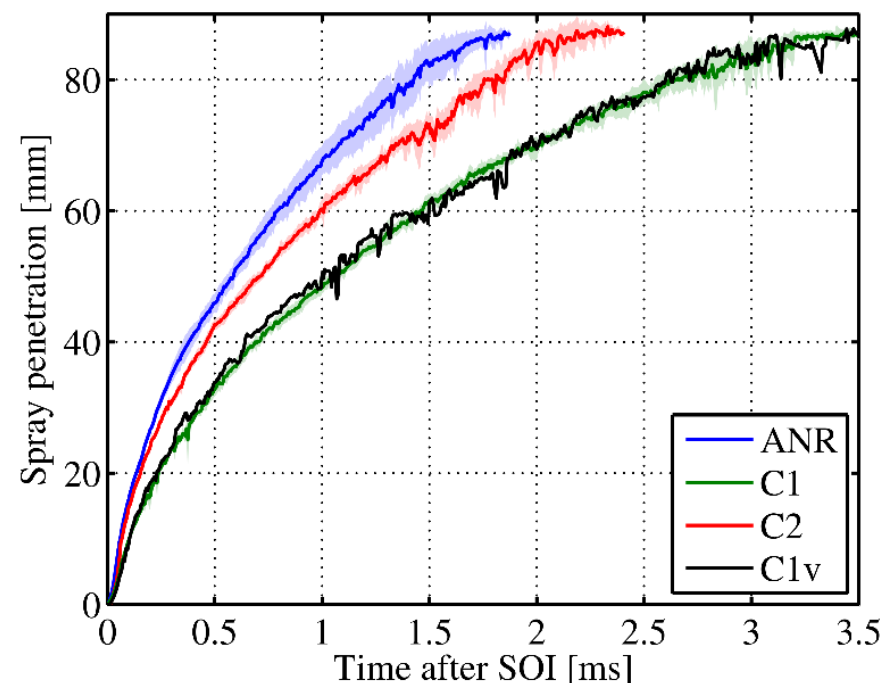

Figure 5. Spray penetration obtained by Schlieren measurements for the conditions listed in Table 2. Light-colored regions around the detected penetration of ANR, C1 and C2 indicate 95\% confidence intervals.

\section{Assessment of numerical models}

Simulations were carried out using a three-dimensional cubical computational mesh which is similar to the vessel used for experiments in terms of volume and size. The structure of the grid intends to reproduce the topology that is commonly adopted to model Diesel engine combustion chambers (Figure 6). To better predict the fuel-air mixing process, local refinement was used in the region where the spray evolves (see Figure 6 (b)), where mesh size ranges from 0.3 to $1 \mathrm{~mm}$.

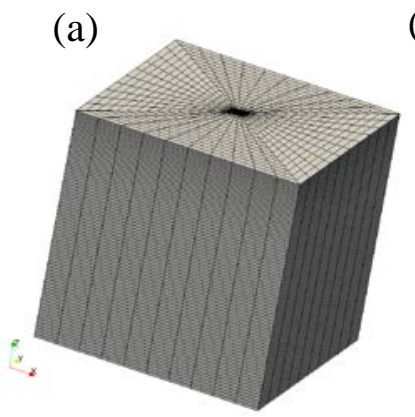

(b)

Figure 6. Computational mesh details: (a) full vessel; (b) mesh structure in the region where the fuel-air mixing process takes place.

CFD simulations were carried out by a compressible segregated solver including the Lagrangian approach for spray modeling. Time derivatives were discretized with the first-order Euler method while second order schemes were used for convection terms. Turbulence was modeled with the standard k- $\varepsilon$ approach. The so-called ANR boundary condition was considered to assess the spray and turbulence models. Grid size effects were not investigated since the mesh resolution is consistent with what was employed in past works by the authors to successfully simulate the combustion process in Diesel engines and at constant-volume conditions [31,33,48].

First, attention was focused on turbulence modeling. The liquid spray transfers momentum and mass to the gas phase which are then diffused inside the computational domain. For a proper prediction of the fuel-air mixing process, a correct estimation of the turbulent viscosity is necessary, since it affects diffusion of species and momentum in the computational domain. It is well known that the standard k- $\varepsilon$ model underpredicts penetration of gas jets, and for this reason, the model constant $C_{\varepsilon 1}$ is generally increased to match experimental data (this is the so-called round jet correction). $C_{\varepsilon 1}$ influences the production rate of $\varepsilon$, which in turn affects the turbulent viscosity field. Matching vapor penetration is important, but the increased momentum diffusion along the spray axis reduces the liquid-gas relative velocity and this might lead to an excessive increase of liquid penetration. For the ANR condition, Figure 7 reports the effects of the $C_{\varepsilon 1}$ turbulence model constant (Equation (2)) on both liquid and vapor penetrations which are defined as the largest distances where $99 \%$ of the mass and 0.001 mixture fraction were found, respectively. Results here are reported for the first $1.5 \mathrm{~ms}$ after start of injection where it is expected that both auto-ignition and establishment of diffusion flame structure will take place. The vapor penetration has a weak dependency on the tuning constants used by the breakup models, while it is strongly affected by the turbulent viscosity distribution: the best agreement with experimental data is achieved when the $C_{\varepsilon 1}$ constant is set to 1.5 and this value was then used in this work. The quasi-steady liquid penetration varies significantly with $C_{\varepsilon 1}$ : from $24 \mathrm{~mm}\left(C_{\varepsilon 1}=1.44\right)$ to $31 \mathrm{~mm}\left(C_{\varepsilon 1}=\right.$ 1.55) since the turbulent viscosity distribution affects the velocity field, which in turn influences the relative liquid-gas velocity. 


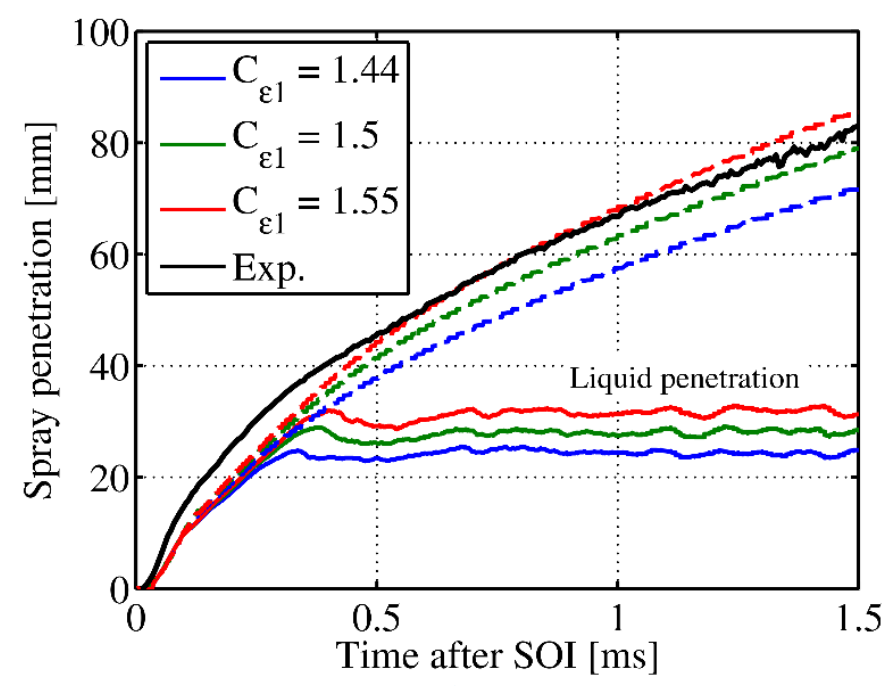

Figure 7. Influence of model constant $C_{\varepsilon 1}$ on the computed spray penetration for the ANR case. Experimental results are represented by a solid black line.

To properly tune the spray sub-models used for atomization and break-up, not only the liquid penetration must be matched, but also the morphology of the spray. Within this context, optical thickness maps of liquid sprays can be very useful to better understand the spray behavior and assess the CFD model accordingly. Three different setups for spray modeling were considered and the used tuning constants are reported in Table 4.

Table 4. Spray model constant parameters for three different approaches of spray modeling.

\begin{tabular}{|l|c|c|c|}
\hline & Setup 1 & Setup 2 & Setup 3 \\
\hline $\mathbf{K}_{\mathbf{c}}$ & 0.45 & 0.45 & 0.45 \\
\hline $\mathbf{K}_{\boldsymbol{\varepsilon}}$ & 0.5 & 0.5 & 0.5 \\
\hline $\mathbf{C}_{\mathbf{d}}$ & 0.662 & 0.662 & 0.662 \\
\hline $\mathbf{C}_{\mathbf{1}}$ & 2.0 & 2.0 & 2.0 \\
\hline $\mathbf{C}_{\mathbf{2}}$ & 0.5 & 0.5 & 0.5 \\
\hline $\mathbf{C}_{\mathbf{3}}$ & 1.0 & 1.0 & 1.0 \\
\hline $\mathbf{C}_{\mathbf{4}}$ & 0.8 & 1.2 & 0.4 \\
\hline $\mathbf{C}_{\mathbf{a}}$ & 1.0 & 1.0 & 1.0 \\
\hline $\mathbf{C}_{\mathbf{2} 2}$ & 0.457 & 0.457 & 0.457 \\
\hline $\mathbf{C}_{\mathbf{5}}$ & 0.5 & 0.5 & 0.7 \\
\hline Strip secondary droplets & No & Yes & Yes \\
\hline Initial spray angle & Eq. (6) & Eq. (6) & 0 \\
\hline Radial velocity deviation & No & No & Yes \\
\hline $\mathbf{B}_{\mathbf{1}}$ & 0.375 & 0.375 & 0.375 \\
\hline $\mathbf{B}_{2}$ & 1.0 & 1.0 & 0.3 \\
\hline
\end{tabular}

Tuning constants were set in order to produce similar values of liquid penetration, in agreement with experimental data for the ANR condition. The main objective of the first setup is to produce a vapor

Page 8 of 18 field without any particular attention to the spray morphology and what happens near the nozzle. Since droplet stripping was disabled, the spray will be only composed of atomizing droplets (reducing their diameter according to Equation (1)), and already atomized ones undergoing secondary breakup. The second setup includes droplet stripping and there the $\mathrm{C}_{4}$ constant was slightly increased with a consequent reduced spray angle. Setup 1 and Setup 2 inject primary parcels, with a velocity direction chosen between 0 and $\alpha$ from Eq. (6), and for both of them the $\mathrm{B}_{2}$ tuning constant of the Pilch-Erdman secondary breakup model was increased to unity. In Setup 3, the velocity direction of the primary parcels is the spray axis and a radial deviation will be only added to the stripped droplets. In order to match experimental liquid penetration data, values of the constants $\mathrm{C}_{4}, \mathrm{C}_{5}$ and $\mathrm{B}_{2}$ were changed. In particular, it was necessary to enhance the jet atomization process, while at the same time reducing the rate at which secondary breakup occurs.

Figure 8 reports a comparison between computed liquid and vapor penetrations from the three setups. All approaches produce very similar values for the liquid penetration. As already commented, vapor penetration is not affected by the spray model constants. However, when droplet stripping is not taken into account, it takes a certain amount of time for fuel vapor to appear, indicated with an arrow in Figure 8. Primary parcels first undergo atomization and evaporation starts only after that, when diameter is further reduced because of secondary breakup and increase of droplet temperatures.

Figure 8 shows one of the typical drawbacks arising from validating models using global parameters such as mass-based liquid penetration. For every setup, parameters were tuned to match the experimental liquid penetration values. However, differences between the computed spray structures are expected and they need to be addressed in detail to identify the configuration producing the best agreement with experimental data. Within this context, novel methodologies suggested in [20,49,50] are expected to deeply analyze the morphology of the spray. In particular, the following quantities are considered:

- $\quad$ Projected mass density ( $P M D$ ): the computed droplet mass is projected on a plane passing through the spray axis. This quantity makes it possible to identify the mechanisms governing spray evaporation.

- $\quad$ Non-dimensional optical thickness $(\tau)$ : suitable post-processing utilities applying the Beer-Lambert law allow a better comparison between computed and measured data used for optical thickness profiles. In this way, the same definition can be applied for the computation of liquid penetration. 


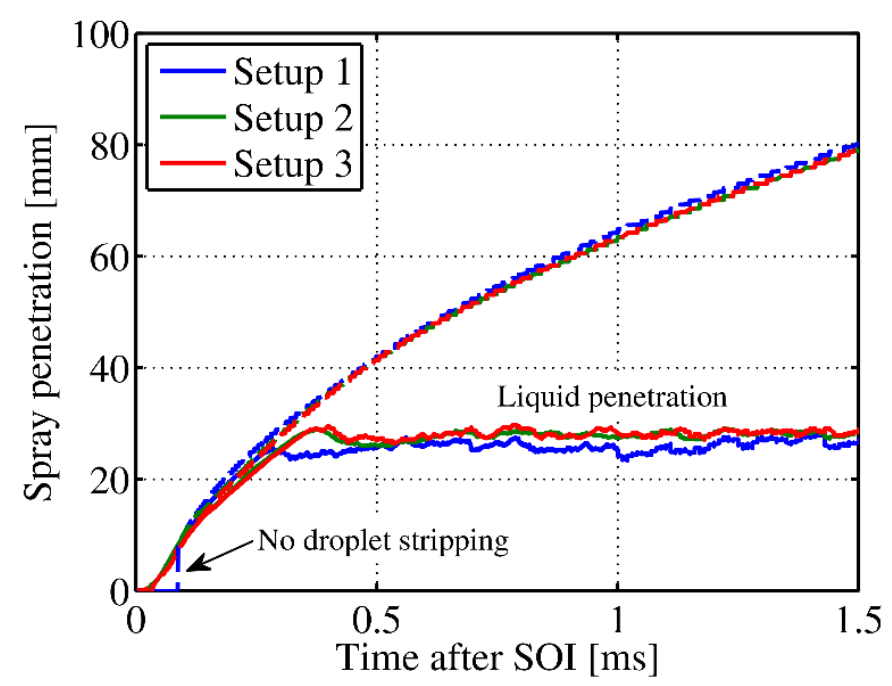

Figure 8. Comparison between computed values of liquid (solid) and vapor (dashed) penetrations as function of the spray breakup model setup.

In order to calculate the projected mass density profiles for the three cases, first a two-dimensional planar mesh was created with a $0.5 \mathrm{~mm}$ uniform resolution. This size ensures that the spray remains dispersed even in the projection process, consistently with the Lagrangian approach. Afterwards, for each parcel in the spray the closest face in the 2D mesh was identified and the projected mass density is computed for each of them as follows:

$$
\operatorname{PMD}(\overrightarrow{\boldsymbol{x}})=\frac{1}{S} \sum_{i=1}^{N_{p}} m_{p}(\overrightarrow{\boldsymbol{x}})
$$

where $N_{p}$ is the number of parcels which are projected on the same face and $m_{p}$ the mass of each of them. $S$ is the face area of the 2D mesh $\left(0.25 \mathrm{~mm}^{2}\right)$. Projected mass density (PMD) profiles were generated for three cases, averaged for the part of the simulation where the liquid penetration reaches a steady-state value. PMD axial distribution is reported in Figure 9(a) together with axial mixture fraction profiles (Figure 9(b)). For sake of completeness, the measured liquid penetration length from DBI is reported too in both figures. Differences in the spray setup are clearly visible already from PMD profiles.

Setup 1 does not consider droplet stripping and atomizing droplets are not subjected to drag. This is the reason why the PMD is almost flat until primary breakup occurs approximately at a 4-mm distance from the nozzle. Afterwards, drag and breakup reduce the droplet velocity, increasing the projected amount of mass. Atomized droplets undergo secondary breakup and heat transfer. At approximately 10 $\mathrm{mm}$ from the nozzle, fuel evaporation starts as it can be seen in Figure 9(b). Looking at PMD and mixture fraction, the evaporation process can be mainly divided into two phases. In the first, PMD still increases because of drag. The second phase starts at a 15-mm distance from the injector, where evaporation rate dominates and PMD is progressively reduced until it becomes zero at a $30-\mathrm{mm}$ distance downstream. The inclusion of droplet stripping (Setup 2) generates a sort of bi-modal droplet distribution due to the simultaneous presence of secondary and primary parcels. The first ones are subjected to drag and this explains the slight increase of PMD compared to Setup 1 before the primary breakup length, $4 \mathrm{~mm}$ downstream of the injector. However, due to their small diameter and the high relative velocity that they experience, the evaporation process starts almost directly at the injector orifice and the PMD becomes lower than the one computed by Setup 1 . The presence of a non-negligible amount of fuel vapor (mixture fraction at $10 \mathrm{~mm}$ is 0.2 ) slows down the evaporation rate for the Setup 2 in the $15-30 \mathrm{~mm}$ region due to a reduced Spalding number. However, where liquid length stabilizes, fuel vapor mixture fraction values are very similar and they decay in the same way due to air entrainment and turbulent diffusion. When the Setup 3 is used, droplets are injected along the spray axis and stripped droplets are also generated there. These are the reasons why PMD profiles are higher for Setup 3. Due to the presence of stripped droplets, vapor distribution is similar to Setup 2 up to $10 \mathrm{~mm}$. At higher distances, mixture fraction from Setup 3 is more similar to the one computed by Setup 1, due to the higher amount of liquid found along the spray axis because of the fixed injection direction.

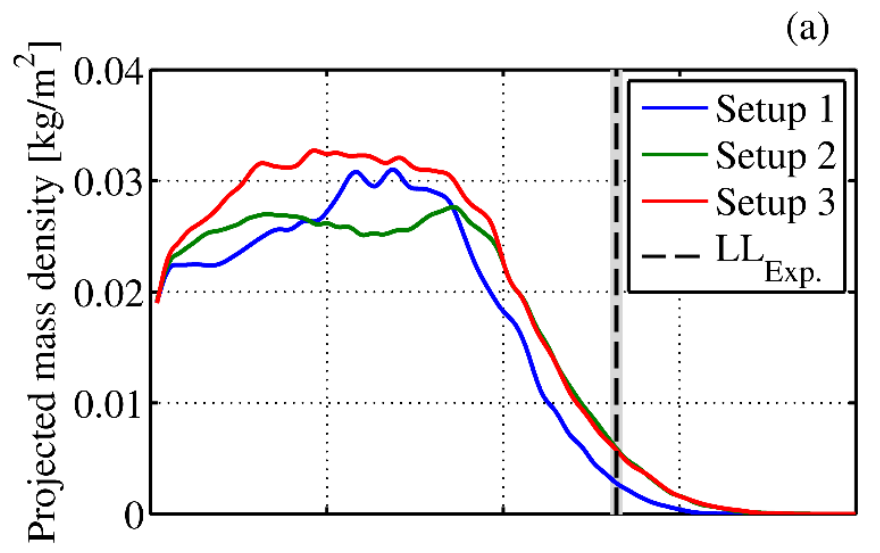

(b)

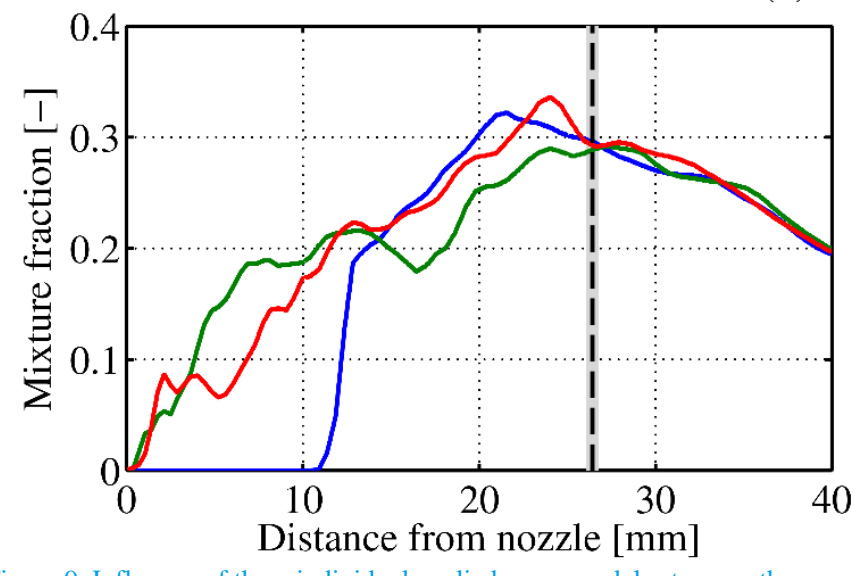

Figure 9. Influence of three individual applied spray model setups on the projected mass density (a) and mixture fraction (b).

Despite the use of different model constants for spray modeling, there are no significant differences in terms of mixture fraction distribution far from the spray, where the diffusion combustion process is expected to occur. However, identification of the correct spray morphology is still necessary to understand when the evaporation process will start. In case the spray behaves like Setup 1, it is expected that the ignition delay time will approximately increase by $0.1 \mathrm{~ms}$ due to the time required for the fuel to atomize and start evaporation.

To further analyze the liquid region, a light scattering model was developed following the recent methods suggested by Magnotti, Grosshans and their co-authors [49,50]. Axial profiles of non-

Page 9 of 18 
dimensional optical thickness $\tau$ were computed assuming the spray to be composed only of spherical liquid droplets. In this model, the liquid phase is non-absorbing and the refractive index for the ambient gas is equal to 1 . In addition to this, effects due to multiple scattering events were neglected. The intensity loss is related to the local extinction coefficient $\mu_{e}$ as:

$$
d I=-\mu_{e} \cdot I \cdot d x
$$

$\mu_{e}$ is an optical quantity depending on the droplet size and number density at a given wavelength. The solution of Equation (22) is the well-known Beer-Lambert law which was used for the experimental data in Equation (20). In this case, the non-dimensional optical thickness $\tau$ is derived by integrating Eq. (22) over the depth of the spray $s$ :

$$
\begin{gathered}
\int_{I_{b g}}^{I} \frac{d I}{I}=\int_{0}^{s}-\mu_{e}(x) \cdot d x \\
-\ln \left(I / I_{b g}\right)=\int_{0}^{s}-\mu_{e}(x) \cdot d x=\tau
\end{gathered}
$$

$\mu_{e}$ depends only on droplet concentration $N$ and the extinction cross section $\sigma_{e}$. When illuminating a monodispersed set of droplets with a monochromatic light source, $\mu_{e}$ can be estimated as [50]:

$$
\mu_{e}=\sigma_{e} \cdot N
$$

If the spherical droplets in the system a have size in the order of $0.1-$ 10 microns, $\sigma_{e}$ can be approximated by twice the size of the geometrical droplet cross-section $\sigma_{g}$ :

$$
\sigma_{e}=\frac{\pi d_{d}^{2}}{2}
$$

Simulated spray data were post-processed to compute the $\tau$ distribution by employing the methodology summarized in Figure 10. First, a two-dimensional planar mesh was built: it is co-axial with the spray and has the same resolution used to collect optical data in the experiments $(77.5 \mu \mathrm{m})$. For each face center of the mesh, a segment orthogonal to the plane was traced, whose length is greater than the spray thickness. The segment is then discretized with a resolution $\Delta x$ which was set equal to $0.01 \mathrm{~mm}$. This results in a number of discretized points $N_{\text {points }}$ which is equal to:

$$
N_{\text {points }}=\frac{x_{\max }-x_{\min }}{\Delta x}
$$

At every point of the segment, a cube with side $\Delta$ s side was considered ( $0.1 \mathrm{~mm}$ in this work) and the number of parcels $N_{p}$ inside it was determined. The corresponding local value of the extinction $\mu_{e}$ was then computed as follows:

$$
\mu_{e}=\sum_{j=1}^{N_{p}} \sigma_{e}\left(D_{p}\right) \cdot \frac{N_{d, i}}{V_{c e l l}}
$$

where $D_{p}$ is the diameter of the droplets in that parcel, and $N_{d, i}$ is the number of droplets for every parcel computed as the ratio between the parcel mass and the liquid density at parcel temperature. $V_{\text {cell }}$ is the cell volume of the three-dimensional mesh. This ensures that the droplet density is consistent with the computed one. $\sigma_{e}$ is computed according to Eq. (26). For every face of the mesh, the corresponding non-dimensional optical thickness is computed by integrating $\mu_{e}$ through the depth of the spray as follows:

$$
\tau^{*}=\sum_{i=1}^{N_{\text {points }}} \frac{1}{V_{\text {cell }}} \mu_{e, i}=\sum_{i=1}^{N_{\text {points }}} \sum_{j=1}^{N_{p}} \sigma_{e}\left(D_{p}\right) \frac{N_{d, i}}{V_{\text {cell }}} \Delta y
$$

Results are function of the chosen values of $\Delta y$ and $\Delta \mathrm{s}$. Both them must be sufficiently small to properly characterize the $\mu_{e}$ distribution through the depth of the spray. Due to this dependence, numerical values of the optical thickness will also be labeled with an asterisk.

\section{Computed $\tau^{*}$ maps}
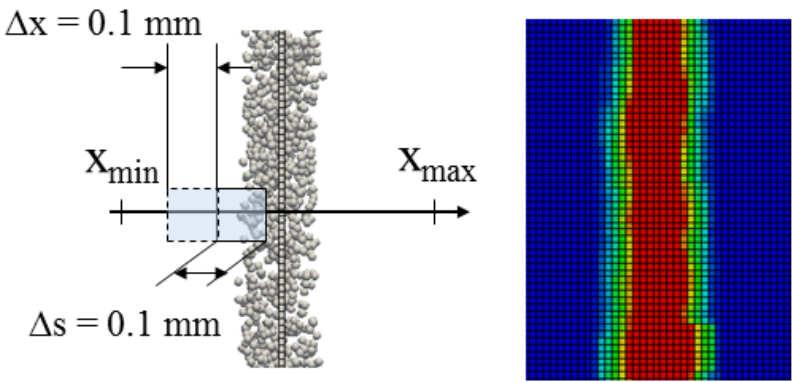

$$
\tau^{*}=\sum_{i=1}^{N_{p o i n t s}} \sum_{j=1}^{N_{p}} \sigma_{e}\left(D_{p}\right) \frac{N_{d, i}}{V_{\text {cell }}} \Delta \mathrm{y}
$$

Figure 10. Methodology to compute the optical thickness from simulated spray data.

To ensure consistency between computed and experimental data, $\tau^{*}$ profiles are sampled every $0.1 \mathrm{~ms}$ and then averaged during the simulation part where the liquid length is steady. A comparison between the computed $\tau^{*}$ axial profiles for the three setup employed is reported in Figure 11(a). The experimental optical thickness profile from the ANR data reported in Figure 3 is displayed as well in order to assess the numerical profiles. Taking droplet stripping into account increases the density of the droplets close to the nozzle. For this reason profiles of $\tau^{*}$ for Setup 2 and 3 rapidly grow up to their maximum value in close proximity of the injector orifice, consistently with what happens in experiments. Differences between the computed and experimental determined values and distributions can be ascribed to three different aspects: the estimation of the extinction cross section, the limited number of sampling intervals used in simulations (300) and the procedure to estimate optical depths from experiments and simulations. As Setup 1 does not consider droplet stripping, $\tau^{*}$ grows only after atomization completes and secondary breakup sufficiently reduces the size of the injected droplets. For all three methods considered, there is no primary breakup after a 4-mm distance from the nozzle. In the region where secondary breakup is the dominating process regulating spray dynamics $(10-20 \mathrm{~mm}$ downstream of the injector orifice), different $\tau^{*}$ peaks are found for the tested spray setup: this is due to the computed droplet distributions along the spray axis resulting in different relative velocity and droplet sizes. In the case of Setup 1, only primary droplets undergo the secondary breakup uniformly distributed over the spray cone. Breakup rate progressively reduces the secondary droplet size with a consequent increase of the corresponding droplet number density $N$ and the associated $\tau^{*}$ value. When droplets reach their stable diameter, spray evolution is only controlled by evaporation and for this reason $\tau^{*}$ progressively decreases after the

Page 10 of 18 
peak and becomes zero at approximately $24 \mathrm{~mm}$ distance from the nozzle. When simulations are carried out using Setup 2, formerly primary parcels and stripped droplets undergoing atomization are found uniformly distributed inside the spray cone. This results in an almost dual-mode droplet distribution and it is likely that stripped droplets reach their stable diameter at the first $\tau^{*}$ peak around $10 \mathrm{~mm}$ while atomized parent droplets, due to their larger diameter, become stable only at a $16 \mathrm{~mm}$ distance from the nozzle at the location of the second peak. Afterwards, evaporation is responsible for the rapid decrease of $\tau^{*}$. The profile obtained by using Setup 3 shows only a single $\tau^{*}$ peak in the secondary breakup region, due to the breakup of the formerly primary parcels. The deviation of the secondary droplets from the axis at the time when they are stripped seems to distribute their breakup more regularly between $4 \mathrm{~mm}$ and the peak at $14 \mathrm{~mm}$. After this peak, evaporation reduces $\tau^{*}$ similarly for Setup 3 until it diminishes to 0 .

For the computation of the steady-state liquid length, the procedure which was used in the experiments was applied to the numerical optical thickness profiles. The dashed lines in Figure 11(a) illustrate how a line is fitted through the decreasing computed optical thickness profile along the injector axis. Similar to the experimental procedure, the intersection of that line with the abscissa represents the steadystate liquid length. Figure 11(b) shows that Setup 3 provides the best agreement with experimental data: the predicted LL is approximately $24.5 \mathrm{~mm}$ versus an experimental value of $26.4 \mathrm{~mm}$ resulting in an absolute error less than $10 \%$. Note however, that the higher penetration of Setup 3 is partially caused by the more gradual decrease of the $\tau^{*}$ profile in the evaporation zone. This behavior is influenced by the presence of large droplets originating from the reduced breakup rate. The other approaches (Setup 1 and 2) predict even lower values compared to Setup 3. A possible reason for such discrepancy can be related to the breakup model used, governing the evolution of droplet size and the onset of their evaporation. In addition to this, grid size can play a role as well, since it is progressively coarsened along the spray axis.

The blue and green columns of Figure 11(b) represent computed penetrations based on the $95 \%$ and $99 \%$ spray mass, respectively. Although commonly used in comparisons between experimental and numerical results, the mass-based approaches do not correlate well with the LL values estimated from optical thickness profiles.

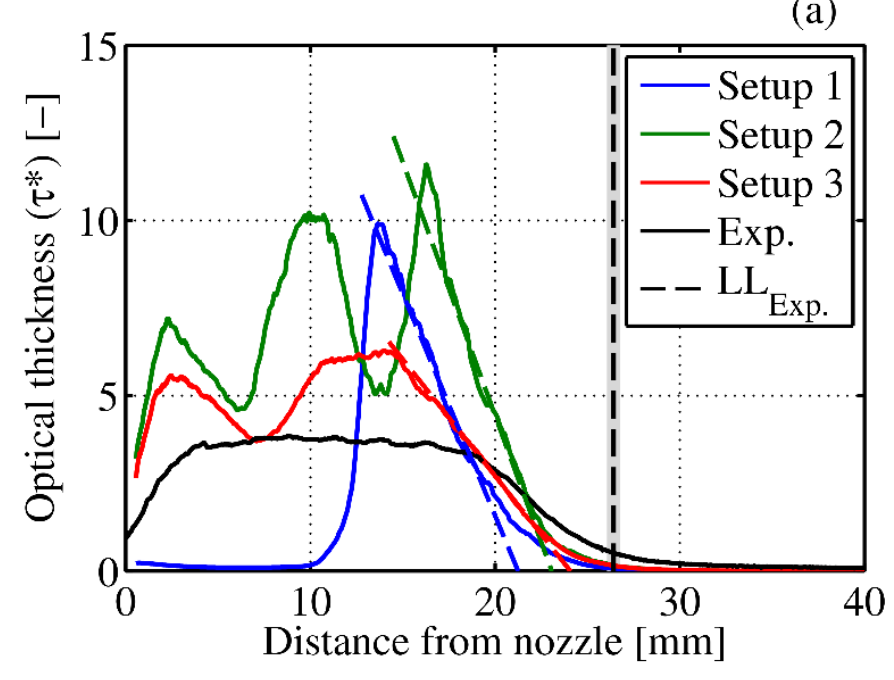

(b)

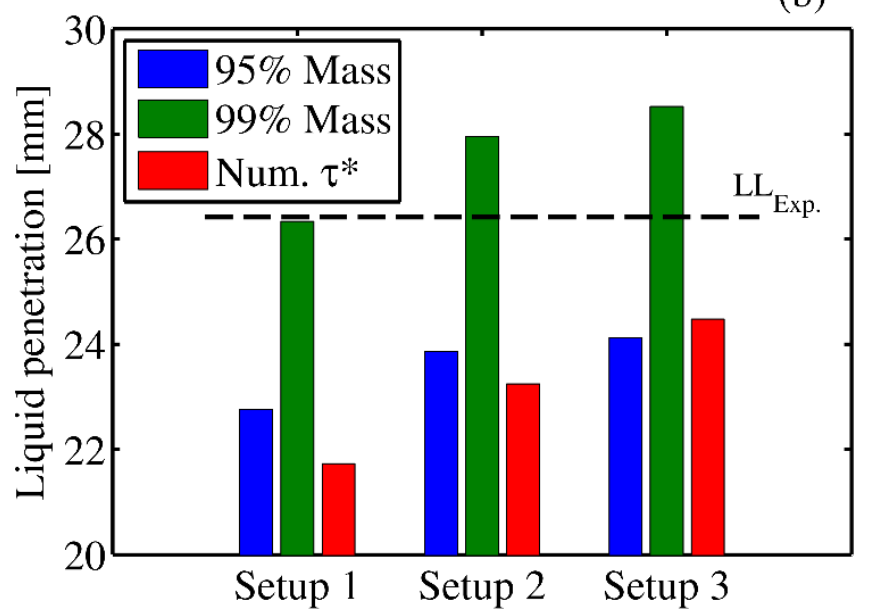

Figure 11. (a): Simulated profiles of the optical thickness for different breakup setups with the experimental fitting procedure to determine the quasi-steady liquid length (illustrated by dashed lines). (b): Comparison between calculated values for the liquid penetrations using the optical thickness and mass-based approaches with different thresholds.

Figure 12 shows a comparison between computed and experimental $\tau^{*}$ distribution in the projection plane for the three different setups. The experimental value of the length at which spray stabilizes (26.4 $\mathrm{mm}$ downstream of the injector orifice) is also reported using a dashed line. The computed spray shape is thinner compared to the experiments, presumably due to the used grid size. Relative velocities in larger cells promote the evaporation of smaller droplets, reducing the radial extension of the spray. Among the tested setups, the spray shape predicted by Setup 3 is in best agreement with experimental data and for this reason it will be adopted for the remainder of the simulations. 

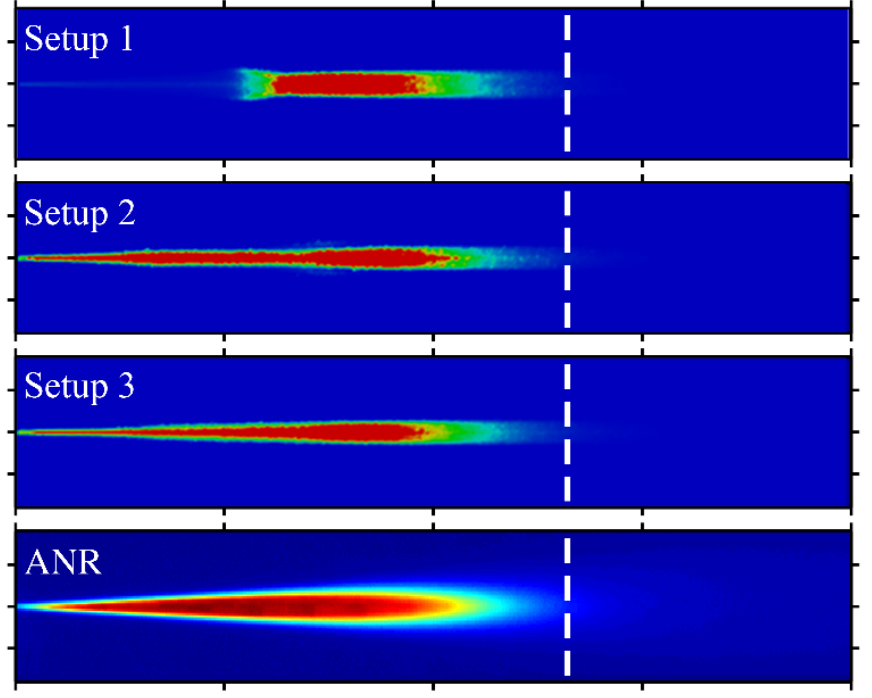

0

10

20

30

40

Axial position [mm]

Figure 12. Comparison of optical thickness maps using different breakup models. White dashed lines indicate the LL value obtained from experimental results.

\section{Validation of results}

The proposed approach for spray modeling is subsequently applied to the simulation of the other two conditions that are characterized by a higher ambient density $\left(40 \mathrm{~kg} / \mathrm{m}^{3}\right)$ and are more representative of full-load conditions in Heavy-Duty Diesel engines at SOI. Figure 13(a) illustrates the computed axial profiles of the optical thickness for the three tested cases (ANR, C1 and C2). Recall that the injection pressure is $80 \mathrm{MPa}$ for the $\mathrm{C} 1$ boundary condition and that it is increased up to $160 \mathrm{MPa}$ for the C2 case. When keeping the ambient density constant, increase of injection pressure enhances both atomization and primary breakup processes, producing smaller droplets. According to Equation (28), this increases the droplet number density and the $\tau^{*}$ value accordingly. In experiments the maximum detected values of the optical thickness do not seem to be related to the operating condition investigated in this work, although they do seem to depend heavily on the fuel properties (see Figure 3). It is expected that the absolute differences in computed and detected optical thickness values are related to the used methods. Recall that both numerical and experimental results were designated as equivalent optical thickness values, due to the influence of numerical parameters and light rays taking a different path to the detector, respectively. In particular, values reported in Figure 13(a) are more similar to those measured using laser extinction techniques rather than DBI. In [51], a spray emerging from a $110 \mu \mathrm{m}$ nozzle was studied at relatively low ambient pressures with different ambient densities (25-40 kg/m ${ }^{3}$ ) and injection pressures (50-180 MPa), reporting maximum $\tau$ values up to 10 . Considering that the nozzle in the current work is larger with a spray which is surely denser, computed values seem to be reasonable. For what concerns the estimation of the liquid length, consistency between laser extinction and DBI was demonstrated by Pickett et al. [46]. Therefore, it is expected that the proposed way to calculate the LL in simulations will produce results which can be properly compared with experimental data.

Page 12 of 18 (a)

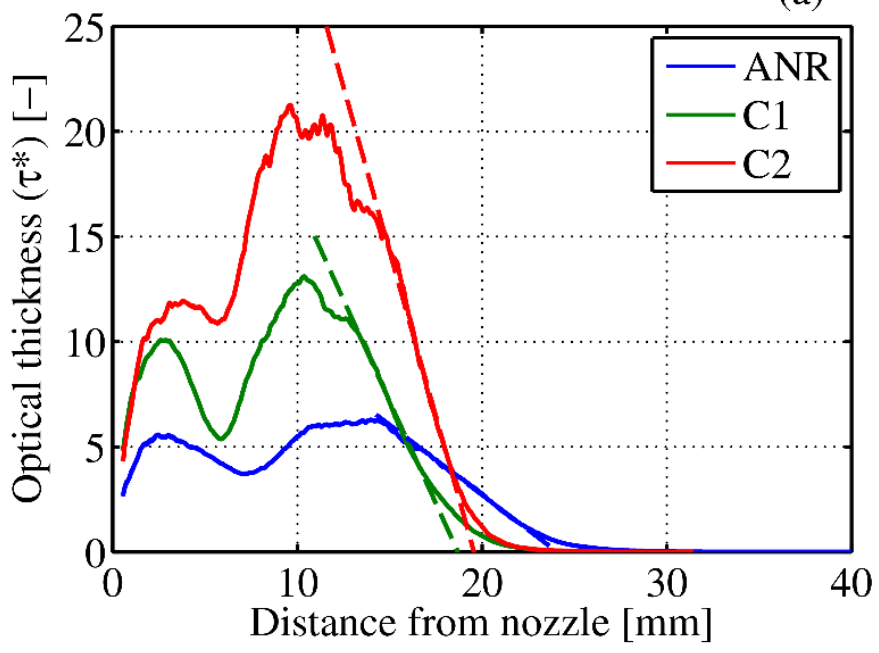

(b)

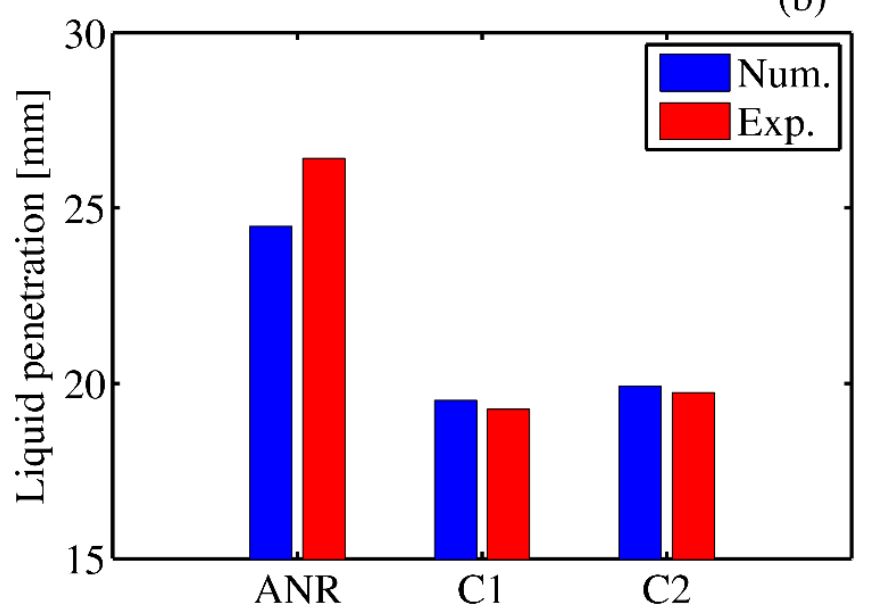

Figure 13. (a) Computed optical thickness profiles along the injector axis for the different boundary conditions. Dashed lines illustrate the fitting procedure to determine the quasi-steady liquid penetration. (b) Comparison between experimental and calculated liquid penetration values for the boundary conditions listed in Table 2.

In the experimental LL values of the high-density cases, it was observed how the counterbalance between the increased rate of injection and enhanced mixing resulted in negligible differences. In the calculations this manifests itself as well. The $\mathrm{C} 2$ condition has a higher spray momentum compared to $\mathrm{C} 1$, but a smaller droplet size at the end of the breakup region and therefore a faster evaporation rate. The determination of the quasi-steady LL using the optical thickness profiles for the three cases is shown in Figure 13(a), where the dashed lines illustrate the fitting procedure. This figure shows, consistently with experimental data, how the ANR condition has the highest liquid penetration due to the reduced ambient density that directly affects the drag force acting on evaporating fuel droplets. The C2 penetration is slightly higher than the C1 case. Figure 13(b) shows the comparison between computed and experimental steadystate liquid penetration values. Effects of ambient density and injection pressure are properly reproduced by simulations and the agreement with experimental data is rather good, especially for the C1 and C2 conditions.

Finally, Figure 14 reports a comparison between computed and experimental 2D optical thickness maps for the three boundary conditions. The significant reduction of liquid penetration due to an 
ambient density increase is observed for both experimental and numerical results. For the C1 and C2 conditions, the spray angle looks smaller compared to experiments. This aspect, which is probably related to the mesh size and the faster evaporation of the droplets at the jet periphery, will be matter of investigation in future studies.

\section{Experimental}
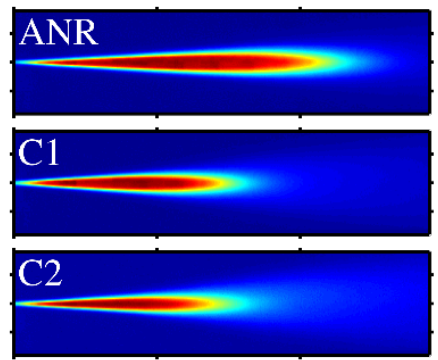

0 10

\section{Calculated}

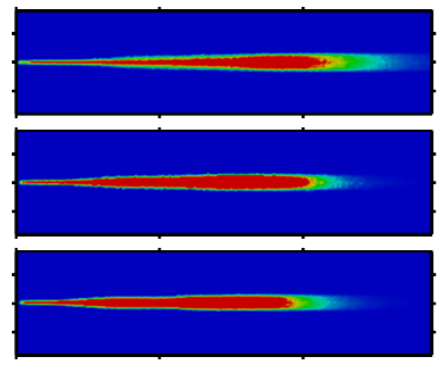

10

20
Axial position $[\mathrm{mm}]$

Figure 14. Left panel: 2-D optical thickness maps obtained with DBI experiments. Right panel: numerical reproduction of the optical thickness maps using simulated liquid spray data.

A comparison between computed and experimental vapor penetration for the three boundary conditions is given in Figure 15. In this figure, dashed lines represent the experimental results with light-colored regions to indicated $95 \%$ confidence intervals. Solid lines represent calculated vapor penetrations using a 0.001 mixture fraction threshold. Unlike the mixing-limited liquid penetration, spray penetration depends on the momentum exchanged between fuel jet and ambient gas. Therefore, increasing injection pressure or ambient density affect the spray penetration in an opposite way. In particular, the ANR condition features the lowest ambient density with an injection pressure of $150 \mathrm{MPa}$, resulting in a relatively fast penetration. For comparison, the ANR jet of the ECN with an injector orifice diameter of $0.09 \mathrm{~mm}$ reaches an axial distance of approximately $55 \mathrm{~mm}$ during the $1.5 \mathrm{~ms}$ time-duration reported in Figure 15 [11]. For the high-density ambient cases, the spray penetration obtained for the $\mathrm{C} 2$ case increases significantly compared to the $\mathrm{C} 1$ boundary conditions due to the $80 \mathrm{MPa}$ difference in injection pressure. Simulated and measured data in Figure 15 agree well and the model is able to capture influences of both injection pressure and ambient density. However, computed penetration values are slightly underestimated in general due to the used $\mathrm{k}-\varepsilon$ turbulence model. A slight increase of the $\mathrm{C} \varepsilon 1$ constant is expected to improve the agreement as depicted in Figure 7. However, this requires further investigation to study the influence on the turbulence model and subsequent liquid penetration values computed from the optical thickness profiles.

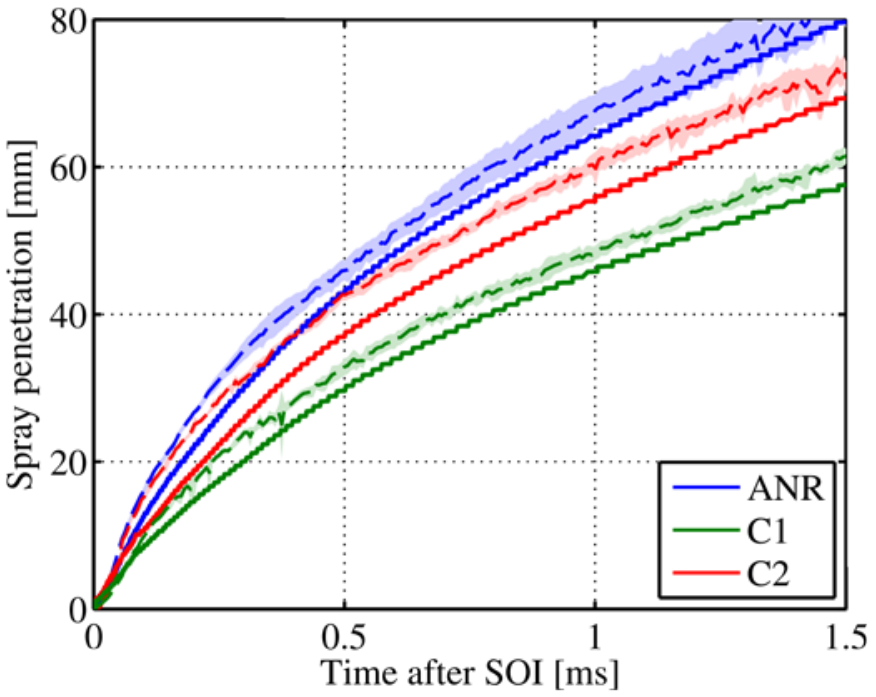

Figure 15. Spray penetration results from experimental (dashed lines) and numerical results (solid lines).

To compare with the RANS results the experimental images are ensemble averaged. This results in a smoother periphery of the spray, and a reduced background distortion compared to the single shot images presented in Figure 4. A time sequence of ensemble averaged Schlieren experiments at inert Spray A conditions is presented in Figure 16. The red contours illustrate a computed mixture fraction threshold of $1 \mathrm{e}-3$, corresponding to the convention used to determine the vapor penetration. By comparing the morphology of the numerical and experimental spray, it can be concluded that the general shape is captured well. The overall underestimation of the spray penetration found in Figure 15 is confirmed by the mixture fraction contour within the softened region downstream in the Schlieren images. From Figure 16, however, it also shows how the extent of the radial spray distribution is generally overestimated by the simulations. The mixture fraction contour encompasses the greater upstream part of the reduced gradients at the experimental spray periphery, although mostly at a constant distance. Overestimation of the spray radial distribution is probably due to the numerical diffusion induced by the coarse mesh structure which is found far from the spray axis. The possibility to use a more refined mesh will be considered in the future. 

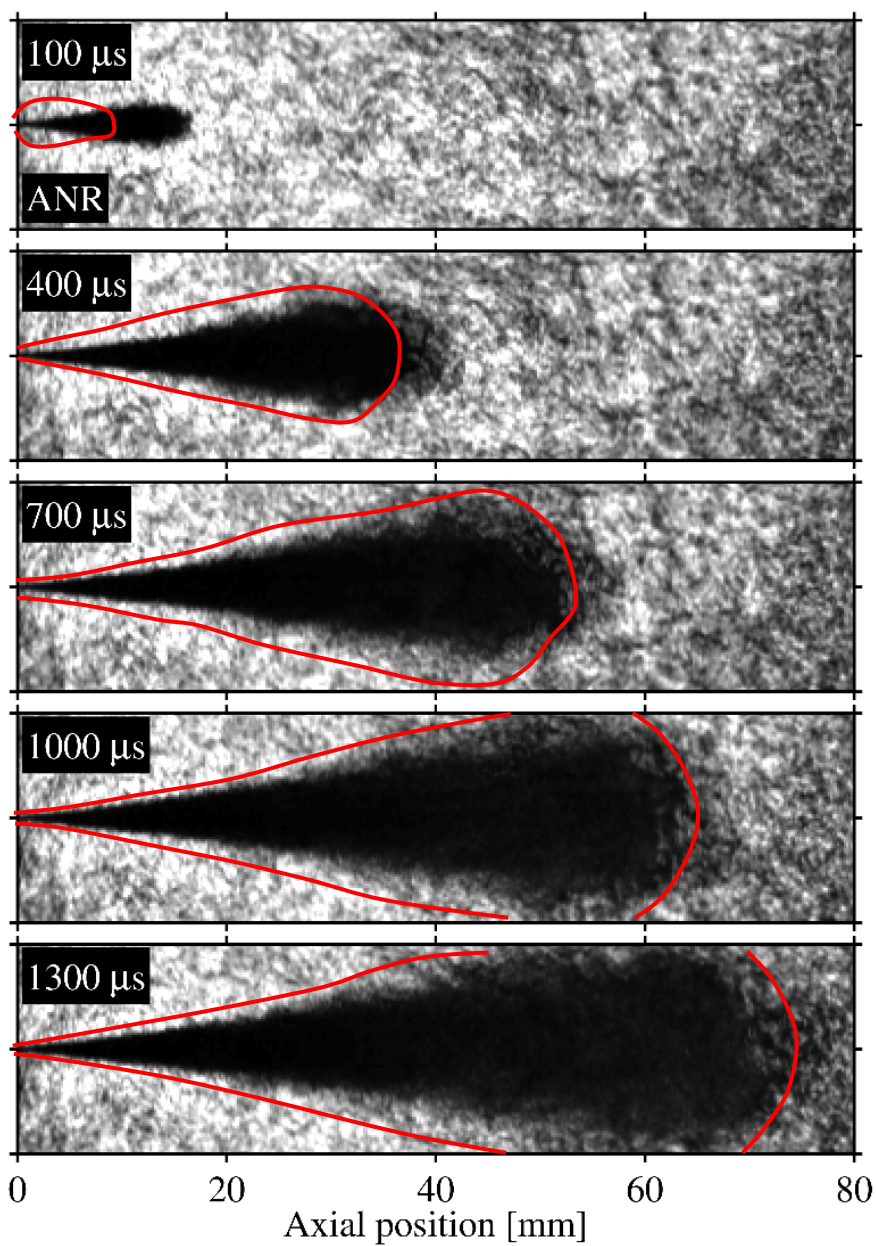

Figure 16. Time sequence of ensemble averaged Schlieren experiments at ANR conditions. The contours represent a numerical mixture fraction threshold of $1 \mathrm{e}-3$.

Figure 17 shows ensemble averaged vapor penetration sequences at the high-density case C1 with the lower injection pressure. Consistently with Figure 15, it is possible to see a reduction of penetration compared to the ANR case due to ambient density increase and injection pressure reduction. Very similar vapor penetration values $(\approx 54 \mathrm{~mm}$ ) were found for both these conditions at 700 (ANR) and 1300 (C1) $\mu$ s. Experiments do not report any relevant change in terms of vapor distribution and this aspect is correctly reproduced by the simulations.
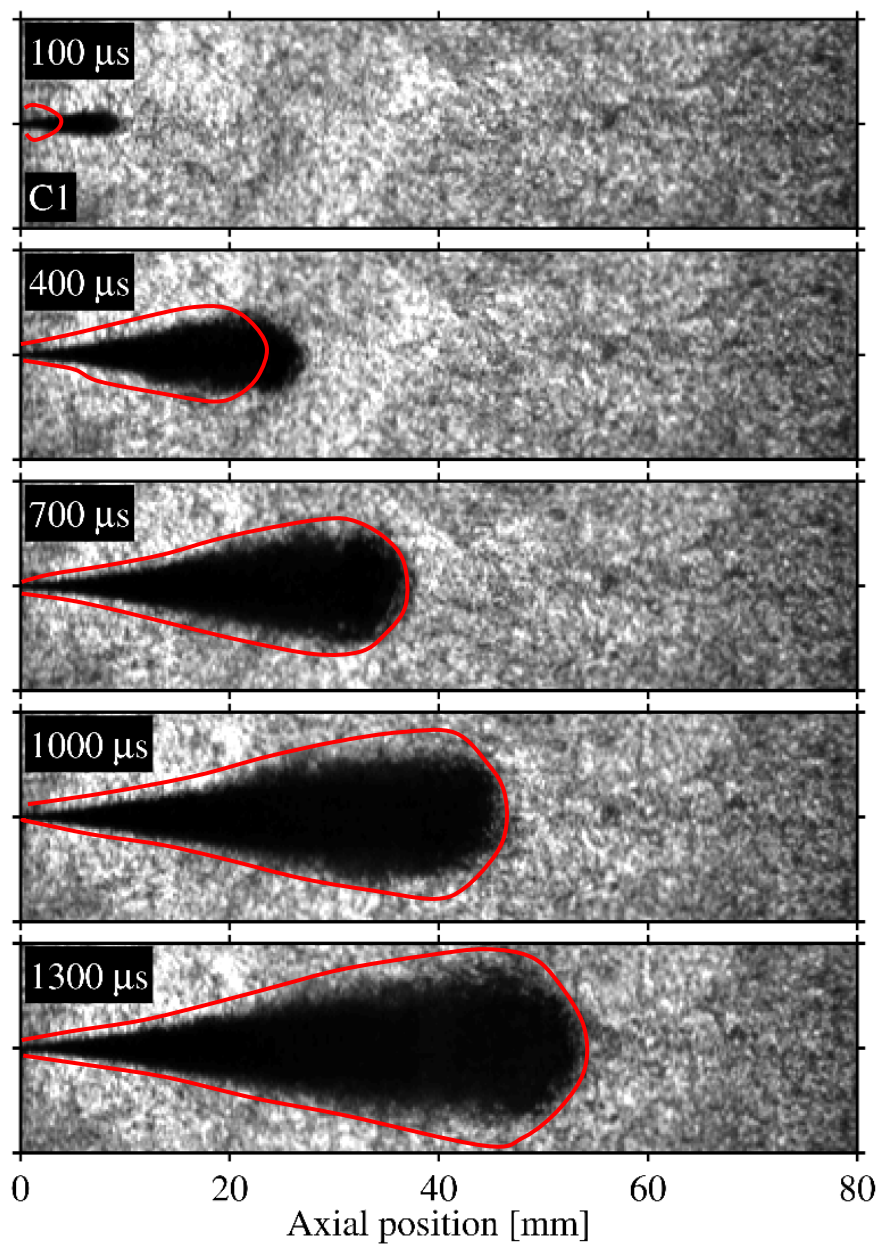

Figure 17. Time sequence of ensemble averaged Schlieren experiments at FPT $\mathrm{C} 1$ conditions. The contours represent a numerical mixture fraction threshold of $1 \mathrm{e}-3$.

\section{Summary and Conclusions}

In this work, a first step towards the characterization of fuel sprays at heavy-duty Diesel engine conditions is presented. Both experimental and numerical results are reported and compared to literature before evaluating the results against each other. The conditions in this study were carefully selected to allow for the comparison with the existing ECN database, and to provide an extension towards a heavy-duty Diesel engine environment with a large orifice diameter injector and high-density ambient. Key findings and conclusions from this work are listed below.

Experiments:

- $\quad$ Liquid penetration experiments using a high-speed DBI imaging arrangement show good agreement with related results and scaling-laws from literature. However, a significant influence on the values of the optical thickness is observed when fuel (and injector) are renewed. Since fixed optical thickness values are often used for transient liquid penetration evaluation, this result indicates that care has to be taken when selecting such a threshold.

- Spray penetration measurements were performed using a highspeed bright-field Schlieren approach. Similar to the liquid penetration results, results show no peculiarities based on 
available data and scaling-laws. To overcome difficulties in distinguishing the fuel spray from background fluctuations, a time-difference approach and ensemble averages have been computed for the spray penetration and morphology, respectively. Spray penetration results were largely reproduced within 95\% confidence intervals after replacement of the injector with a nominally identical piece.

Simulations:

- The use of extinction profiles to determine spray penetration represents an important step towards a more accurate assessment of spray models and a deep understanding of the complex interplay between atomization, secondary breakup and evaporation.

- Based on the performed analysis, atomization models play a non-negligible role in the evolution of evaporating fuel sprays. However, such models require detailed information related to nozzle flow (nozzle $\mathrm{Cd}, \mathrm{k}$ and $\varepsilon$ at nozzle exit).

- $\quad$ The developed methodology, combining Huh-Gosman atomization and Pilch-Erdman breakup models is able to reproduce the effects of ambient density and injection pressure on liquid fuel penetration.

- Results show how the standard k- $\varepsilon$ model with the round-jet correction can be employed to properly predict the fuel-air mixing process in Heavy-Duty Diesel engines.

The results from this work have provided experience and shown insight in the injection of liquid fuel at high-temperature and highpressure conditions, relevant for heavy-duty applications. The aim is to use these insights and developments to further expand this work and improve the understanding and capability to numerically reproduce fuel sprays at heavy-duty Diesel engine conditions.

\section{References}

1. Heywood, J.B., "Internal Combustion Engine Fundamentals,” (New York, McGraw-Hill Education, 1988), ISBN 978 0-07100499-2.

2. Han, Z., Uludogan, A., Hampson, G., and Reitz, R., "Mechanism of Soot and NOx Emission Reduction Using Multiple-injection in a Diesel Engine," SAE Technical Paper 960633, 1996, doi:10.4271/960633.

3. Akihama, K., Takatori, Y., Inagaki, K., Sasaki, S. et al., "Mechanism of the Smokeless Rich Diesel Combustion by Reducing Temperature,” SAE Technical Paper 2001-01-0655, 2001, doi:10.4271/2001-01-0655.

4. Kook, S., Bae, C., Miles, P., Choi, D. et al., "The Influence of Charge Dilution and Injection Timing on Low-Temperature Diesel Combustion and Emissions,” SAE Technical Paper 200501-3837, 2005, doi:10.4271/2005-01-3837.

5. Rutland, C., Ayoub, N., Han, Z., Hampson, G. et al., "Diesel Engine Model Development and Experiments," SAE Technical Paper 951200, 1995, doi:10.4271/951200.

6. Tao, F., Liu, Y., RempelEwert, B., Foster, D. et al., "Modeling the Effects of EGR and Injection Pressure on Soot Formation in a High-Speed Direct-Injection (HSDI) Diesel Engine Using a Multi-Step Phenomenological Soot Model,” SAE Technical Paper 2005-01-0121, 2005, doi:10.4271/2005-01-0121.

7. Baert, R., Frijters, P., Somers, B., Luijten, C. et al., "Design and Operation of a High Pressure, High Temperature Cell for HD Diesel Spray Diagnostics: Guidelines and Results,” SAE
Technical Paper 2009-01-0649, 2009, doi:10.4271/2009-01$\underline{0649}$.

8. Pickett, L., Genzale, C., Bruneaux, G., Malbec, L. et al., "Comparison of Diesel Spray Combustion in Different HighTemperature, High-Pressure Facilities,” SAE Int. J. Engines 3(2):156-181, 2010, doi:10.4271/2010-01-2106.

9. Meijer, M., Somers, B., Johnson, J., Naber, J. et al., “Engine Combustion Network (ECN): Characterization and Comparison of Boundary Conditions for Different Combustion Vessels," Atomization and Sprays 22(9):777-806, 2012, doi:10.1615/AtomizSpr.2012006083.

10. Pickett, L.M., "Engine Combustion Network data archive," http://www.sandia.gov/ECN/, September 2015.

11. Bardi, M., Payri, R., Malbec, L.-M., Bruneaux, G. et al., "Engine Combustion Network (ECN): Comparison of Spray Development, Vaporization and Combustion in Different Combustion Vessels,” Atomization and Sprays 22(10):807-842, 2012, doi:10.1615/AtomizSpr.2013005837.

12. Kastengren, A.L., Tilocco, F.Z., Powell, C.F., Manin, J. et al., "Engine Combustion Network (ECN): Measurements of Nozzle Geometry and Hydraulic Behavior," Atomization and Sprays 22(12):1011-1052, doi:10.1615/AtomizSpr.2013006309.

13. D'Errico, G., Lucchini, T., Contino, F., Jangi, M. et al., "Comparison of Well-Mixed and Multiple Representative Interactive Flamelet Approaches for Diesel Spray Combustion Modelling," Combustion Theory and Modelling 18 (1):65-88, 2014, doi:10.1080/13647830.2013.860238.

14. Lucchini, T., D'Errico, G., Ettorre, D., "Numerical Investigation of the Spray-Mesh-Turbulence Interactions for High-Pressure, Evaporating Sprays at Engine Conditions,” International Journal of Heat and Fluid Flow 32 (1):285-297, 2011, doi:10.1016/j.ijheatfluidflow.2010.07.006.

15. Naber, J. and Siebers, D., "Effects of Gas Density and Vaporization on Penetration and Dispersion of Diesel Sprays," SAE Technical Paper 960034, 1996, doi:10.4271/960034.

16. Siebers, D., "Liquid-Phase Fuel Penetration in Diesel Sprays," SAE Technical Paper 980809, 1998, doi:10.4271/980809.

17. Siebers, D., "Scaling Liquid-Phase Fuel Penetration in Diesel Sprays Based on Mixing-Limited Vaporization,” SAE Technical Paper 1999-01-0528, 1999, doi:10.4271/1999-01-0528.

18. Higgins, B. and Siebers, D., "Measurement of the Flame LiftOff Location on DI Diesel Sprays Using OH Chemiluminescence,” SAE Technical Paper 2001-01-0918, 2001, doi:10.4271/2001-01-0918.

19. Johnson, J., Ge, H., Naber, J., Lee, S. et al., “Investigation of Key Mechanisms for Liquid Length Fluctuations in Transient Vaporizing Diesel Sprays," SAE Int. J. Engines 6(2):1202-1212, 2013, doi:10.4271/2013-01-1594.

20. Manin, J., Bardi, M. and Pickett L.M., "Evaluation of the Liquid Length via Diffused Back-Illumination Imaging in Vaporizing Diesel Sprays,” COMODIA, 2012.

21. Meijer, M., Malbec, L-M., Bruneaux, G., Somers, L.M.T., "Engine Combustion Network: "Spray A" Basic Measurements and Advanced Diagnostics,” ICLASS, Heidelberg, Germany, September 2012.

22. Meijer, M., Galle, J., Somers, L., Griensven, J. et al., "HighSpeed Characterization of ECN Spray A Using Various Diagnostic Techniques,” SAE Int. J. Engines 6(2):1238-1248, 2013, doi:10.4271/2013-01-1616.

23. Malbec, L., Egúsquiza, J., Bruneaux, G., and Meijer, M., "Characterization of a Set of ECN Spray A Injectors: Nozzle to Nozzle Variations and Effect on Spray Characteristics," SAE Int. J. Engines 6(3):1642-1660, 2013, doi:10.4271/2013-24-0037. 
24. Pickett, L., Manin, J., Payri, R., Bardi, M. et al., “Transient Rate of Injection Effects on Spray Development,” SAE Technical Paper 2013-24-0001, 2013, doi:10.4271/2013-24-0001.

25. Pickett, L., Manin, J., Kastengren, A., and Powell, C., "Comparison of Near-Field Structure and Growth of a Diesel Spray Using Light-Based Optical Microscopy and X-Ray Radiography,” SAE Int. J. Engines 7(2):1044-1053, 2014, doi:10.4271/2014-01-1412.

26. Jung, Y., Manin, J., Skeen, S., and Pickett, L., "Measurement of Liquid and Vapor Penetration of Diesel Sprays with a Variation in Spreading Angle,” SAE Technical Paper 2015-01-0946, 2015, doi:10.4271/2015-01-0946.

27. Meijer, M., Christians, R.J., Griensven, J.G.H., Somers, L.M.T. et al., "Engine Combustion Network: Implementation and Analysis of Combustion Vessel Spray A Conditions,” ILASS Americas, Ventura, CA, May 2011.

28. Oren, D., Wahiduzzaman, S., and Ferguson, C., “A Diesel Combustion Bomb: Proof of Concept,” SAE Technical Paper 841358, 1984, doi:10.4271/841358.

29. Pastor, J., García, J., Pastor, J., and Zapata, L., "Evaporating Diesel Spray Visualization using a Double-pass Shadowgraphy/Schlieren imaging," SAE Technical Paper 200724-0026, 2007, doi:10.4271/2007-24-0026.

30. Skeen, S., Manin, J., and Pickett, L., "Visualization of Ignition Processes in High-Pressure Sprays with Multiple Injections of nDodecane,” SAE Int. J. Engines 8(2):696-715, 2015, doi:10.4271/2015-01-0799.

31. D'Errico, G., Lucchini, T., Hardy, G., Tap, F. et al., "Combustion Modeling in Heavy Duty Diesel Engines Using Detailed Chemistry and Turbulence-Chemistry Interaction,” SAE Technical Paper 2015-01-0375, 2015, doi:10.4271/201501-0375.

32. Lucchini, T., D'Errico, G., Onorati, A., Bonandrini, G. et al., "Development and Application of a Computational Fluid Dynamics Methodology to Predict Fuel-Air Mixing and Sources of Soot Formation in Gasoline Direct Injection Engines," International Journal of Engine Research 15(5):581-596, 2014, doi: $10.1177 / 1468087413500297$.

33. Lucchini, T., Della Torre, A., D'Errico, G., Montenegro, G. et al., "Automatic Mesh Generation for CFD Simulations of Direct-Injection Engines,” SAE Technical Paper 2015-01-0376, 2015, doi:10.4271/2015-01-0376.

34. Lucchini, T., D'Errico, G., Ettorre, D., Brusiani, F. et al., "Experimental and Numerical Investigation of High-Pressure Diesel Sprays with Multiple Injections at Engine Conditions," SAE Technical Paper 2010-01-0179, 2010, doi:10.4271/201001-0179.

35. Lucchini, T., Fiocco, M., Onorati, A., Montanaro, A. et al., "Full-Cycle CFD Modeling of Air/Fuel Mixing Process in an Optically Accessible GDI Engine," SAE Int. J. Engines 6(3):1610-1625, 2013, doi:10.4271/2013-24-0024.

36. Huh, K. Y., and A. D. Gosman, "A Phenomenological Model of Diesel Spray Atomization,” Proceedings of the International Conference on Multiphase Flows, Tsukuba, Japan, 1991.

37. Huh, K. Y., Lee, E., Koo, J., "Diesel Spray Atomization Model Considering Nozzle Exit Turbulence Conditions," Atomization and Spray 8(4):453-469, 1998, doi:10.1615/AtomizSpr.v8.i4.60.

38. Hinze, J. O., "Fundamentals of the Hydrodynamic Mechanism of Splitting in Dispersion Processes," AIChE Journal 1(3):289295, 1955, doi:10.1002/aic.690010303.

39. Faeth, G. M., Hsiang, L.P., Wu, P. K., "Structure and Breakup Properties of Sprays,” Int. J. Multiphase Flow 21, 99-127, 1995, doi:10.1016/0301-9322(95)00059-7.

40. Bode, M., Falkenstein, T., Le Chenadec, V., Kang, S. et al., “A New Euler/Lagrange Approach for Multiphase Simulations of a

Page 16 of 18
Multi-Hole GDI Injector,” SAE Technical Paper 2015-01-0949, 2015, doi:10.4271/2015-01-0949.

41. Xue, Q., Battistoni, M., Powell, C.F., Quan, S., et al., “An Eulerian CFD Model and X-ray Radiography for Coupled Nozzle Flow and Spray in Internal Combustion Engines,” Int. J. Multi-phase Flows 70:77-88, 2015, doi:10.1016/j.ijmultiphaseflow.2014.11.012.

42. Brusiani, F., Bianchi, G., Falfari, S., Onorati, A. et al., "Influence of Cylindrical, k, and ks Diesel Nozzle Shape on the Injector Internal Flow Field and on the Emerging Spray Characteristics,” SAE Technical Paper 2014-01-1428, 2014, doi:10.4271/2014-01-1428.

43. Pilch, M., and Erdman, C. A., "Use of Breakup Time Data and Velocity History Data to Predict the Maximum Size of Stable Fragments for Acceleration-Induced Breakup of a Liquid Drop,” Int. J. Multiphase Flow 13(6):741-757, 1987, doi:10.1016/03019322(87)90063-2.

44. Payri, R., García, J.M., Salvador, F.J., Gimeno, J., “Using Spray Momentum Flux Measurements to Understand the Influence of Diesel Nozzle Geometry on Spray Characteristics,” Fuel 84(5):551-561, 2005, doi:10.1016/j.fuel.2004.10.009.

45. Salvador, F.J., Romero, J.-V., Roselló, M.-D. Martínez-López, J., "Validation of a code for modeling cavitation phenomena in Diesel injector nozzles," Mathematical and Computer Modelling 52(7-8):1123-1132, 2010, doi:10.1016/j.mcm.2010.02.027.

46. Pickett, L.M., Genzale, C.L., Manin, J., Malbec, L.M. et al., "Measurement Uncertainty of Liquid Penetration in Evaporating Diesel Sprays,” ILASS Americas, Ventura, CA, May 2011.

47. Pickett, L., Kook, S., and Williams, T., "Visualization of Diesel Spray Penetration, Cool-Flame, Ignition, High-Temperature Combustion, and Soot Formation Using High-Speed Imaging," SAE Int. J. Engines 2(1):439-459, 2009, doi:10.4271/2009-01$\underline{0658}$.

48. D'Errico, G., Lucchini, T., Onorati, A., Hardy, G., "Computational fluid dynamics modeling of combustion in heavy-duty diesel engines,” Int. J. Engine Research 16(1):112124, 2015, doi:10.1177/1468087414561276.

49. Magnotti, G. and Genzale, C., "A Novel Approach to Assess Diesel Spray Models using Joint Visible and X-Ray Liquid Extinction Measurements," SAE Int. J. Fuels Lubr. 8(1):167178, 2015, doi:10.4271/2015-01-0941.

50. Grosshans, H., Kristensson, E., Szász, R.-Z., Berrocal, E., "Prediction and Measurement of the local extinction coefficient in sprays for 3D simulation/experiment data comparison,” Int. J. Multiphase Flow (72):218-232, 2015, doi:10.1016/j.ijmultiphaseflow.2015.01.009.

51. Payri, F., Pastor, J. V., Payri, R., Manin, J., "Determination of the optical depth of a DI diesel spray," Journal of Mechanical Science and Technology 25(1):209-219, 2011, doi: 10.1007/s12206-010-1024-X.

\section{Contact Information}

Noud Maes

Department of Mechanical Engineering

Eindhoven University of Technology

P.O. Box 513

5600 MB, Eindhoven, The Netherlands

n.c.j.maes@tue.nl

Prof. Gianluca D'Errico

Department of Energy, Politecnico di Milano

Via Lambruschini, 4

20156 Milano, Italy 


\section{Acknowledgments}

Experiments were conducted at the Combustion Technology facility of the Eindhoven University of Technology. Financial support for this work was provided by FPT-Motorenforschung AG. Michael Harter, Hans van Griensven and Theo de Groot are acknowledged for their excellent technical support.

\section{Definitions/Abbreviations}

$*$

$\mathbf{B}_{1}-\mathbf{B}_{2} \quad$ Tuning coefficients of the breakup model

$\mathbf{C}_{1}-\mathbf{C}_{5} \quad$ Spray model constants

$\mathbf{C}_{\mathbf{a} 1}-\mathbf{C}_{\mathbf{a} 2} \quad$ Turbulent evolution constants

$\boldsymbol{C}_{\boldsymbol{\varepsilon} \mathbf{1}}-\boldsymbol{C}_{\varepsilon 5} \quad$ Turbulence model constants

C $\quad$ Discharge coefficient

$\boldsymbol{C}_{\boldsymbol{\mu}} \quad \mathrm{k}-\varepsilon$ model constant

D Nozzle orifice diameter

Dd Droplet diameter

$\mathbf{D}_{\mathbf{p}} \quad$ Parcel diameter

Ds Maximum stable droplet diameter

dj $\quad$ Parcel diameter

I Intensity

Ibg Intensity of the background

K $\quad$ Form loss coefficient

$\mathbf{K}_{\varepsilon} \quad$ Turbulent modeling constant

k Turbulent kinetic energy

L Nozzle orifice length

La Atomization length scale

Lt Turbulent length scale

$\mathbf{L}_{\mathbf{w}} \quad$ Perturbation wavelength on the jet surface $\mathbf{m}_{\mathbf{p}}$

$\mathbf{N}$

$\mathbf{N}_{\mathbf{p}}$

$\mathbf{N}_{\text {points }}$

$\mathbf{n}_{\mathbf{p}}$

Oh

S

S

$u_{\text {rel }}$

$U_{i n j}$

$\mathbf{V}_{\text {cell }}$

$\mathbf{V}_{\mathbf{d}}$

$v_{r}$

We

$W e_{c}$

$\alpha$

$\varepsilon$

$\boldsymbol{\mu}_{\boldsymbol{e}}$

$\rho_{1}$

$\rho_{\mathrm{g}}$

$\sigma_{1}$

$\sigma_{\mathbf{e}}$

$\sigma_{\mathrm{g}}$

$\tau$

$\tau_{\boldsymbol{a}}$

$\tau_{t}$

$\tau_{w}$

ANR
Mass of parcels

Droplet concentration

Number of parcels on a face

Number of discretized points

Number of parent droplets

Ohnesorge number

Face area of the 2D mesh

Area ratio at the contraction corner

Relative liquid-gas velocity

Instantaneous jet velocity

Cell volume of the 3D mesh

Droplet volume

Radial velocity

Weber number

Critical Weber number

Spray cone angle

Turbulent dissipation

Local extinction coefficient

Liquid density

Gas density

Surface tension

Extinction cross section

Geometrical cross section

Optical thickness

Atomization time scale

Turbulent time scale

Aerodynamic time scale

Spray A, Non-Reacting 
ASOI

CFD Computational Fluid Dynamics

DBI Diffused Back-Illumination

ECN Engine Combustion Network

FPT Fiat Powertrain Technologies

LED Light-Emitting Diode
LL Liquid-Length

PFD Probability Density Function

PMD Projected Mass Density

RANS Reynolds-averaged Navier-Stokes

SOI Start Of Injection 